Boise State University

ScholarWorks

Physics Faculty Publications and Presentations

Department of Physics

$1-2021$

\title{
Interaction of Alpha-Crystallin with Four Major Phospholipids of Eye Lens Membranes
}

\author{
Raju Timsina \\ Boise State University \\ Nawal K. Khadka \\ Boise State University \\ David Maldonado \\ Boise State University \\ Laxman Mainali \\ Boise State University
}

\section{Publication Information}

Timsina, Raju; Khadka, Nawal K.; Maldonado, David; and Mainali, Laxman. (2021). "Interaction of AlphaCrystallin with Four Major Phospholipids of Eye Lens Membranes". Experimental Eye Research, 202, 108337. https://doi.org/10.1016/j.exer.2020.108337

This is an author-produced, peer-reviewed version of this article. (c) 2021, Elsevier. Licensed under the Creative Commons Attribution-NonCommercial-No Derivatives 4.0 license. The final, definitive version of this document can be found online at Experimental Eye Research, https://doi.org/10.1016/j.exer.2020.108337 


\title{
Interaction of Alpha-Crystallin with Four Major Phospholipids of Eye Lens Membranes
}

\author{
Raju Timsina \\ Department of Physics \\ Boise State University \\ Boise, ID, USA \\ David Maldonado \\ Department of Mechanical Engineering \\ Boise State University \\ Boise, ID, USA
}

\author{
Nawal K. Khadka \\ Department of Physics \\ Boise State University \\ Boise, ID, USA \\ Laxman Mainali* \\ Department of Physics \\ Boise State University \\ Boise, ID, USA \\ and \\ Biomolecular Sciences Graduate Program \\ Boise State University \\ Boise, ID, USA \\ laxmanmainali@boisestate.edu
}

\begin{abstract}
It is well-studied that the significant factor in cataract formation is the association of $\alpha$-crystallin, a major eye lens protein, with the fiber cell plasma membrane of the eye lens. The fiber cell plasma membrane of the eye lens consists of four major phospholipids (PLs), i.e., phosphatidylcholine (PC), phosphatidylethanolamine (PE), phosphatidylserine (PS), and sphingomyelin (SM). Despite several attempts to study the interaction of $\alpha$-crystallin with PLs of the eye lens membrane, the role of individual PL for the binding with $\alpha$-crystallin is still unclear. We recently developed the electron paramagnetic resonance (EPR) spin-labeling method to study the binding of $\alpha$-crystallin to the PC membrane (Mainali et al., 2020a). Here, we use the recently developed EPR method to explicitly measure the binding affinity $\left(\mathrm{K}_{\mathrm{a}}\right)$ of $\alpha$ crystallin to the individual (PE*, PS, and $\mathrm{SM}$ ) and two-component mixtures (SM/PE, SM/PS, and $\mathrm{SM} / \mathrm{PC}$ in 70:30 and 50:50 mol\%) of PL membranes as well as the physical properties (mobility parameter and maximum splitting) of these membranes upon binding with $\alpha$-crystallin. One of the key findings of this study was that the $\mathrm{K}_{\mathrm{a}}$ of $\alpha$-crystallin binding to individual PL membranes followed the trends: $\mathrm{K}_{\mathrm{a}}(\mathrm{PC})>\mathrm{K}_{\mathrm{a}}(\mathrm{SM})>\mathrm{K}_{\mathrm{a}}(\mathrm{PS})>\mathrm{K}_{\mathrm{a}}\left(\mathrm{PE}^{*}\right)$, indicating PE* inhibits binding the most whereas PC inhibits binding the least. Also, the $\mathrm{K}_{\mathrm{a}}$ of $\alpha$-crystallin binding to two-component mixtures of PL membranes followed the trends: $\mathrm{K}_{a}(\mathrm{SM} / \mathrm{PE})>\mathrm{K}_{a}(\mathrm{SM} / \mathrm{PS})>$ $\mathrm{K}_{\mathrm{a}}(\mathrm{SM} / \mathrm{PC})$, indicating $\mathrm{SM} / \mathrm{PC}$ inhibits binding the most whereas $\mathrm{SM} / \mathrm{PE}$ inhibits binding the least. Except for the PE* membrane, for which there was no binding of $\alpha$-crystallin, the mobility parameter for all other membranes decreased with an increase in $\alpha$-crystallin concentration. It represents that the membranes become more immobilized near the headgroup regions of the PLs when more and more $\alpha$-crystallin binds to them. The maximum splitting increased only for the $\mathrm{SM}$ and the SM/PE (70:30 mol\%) membranes, with an increase in the binding of $\alpha$-crystallin. It represents that the PL headgroup regions of these membranes become more ordered after binding of $\alpha$-crystallin to these membranes. Our results showed that $\alpha$-crystallin binds to PL membranes in a saturable manner. Also, our data suggest that the binding of $\alpha$-crystallin to PL membranes likely occurs through hydrophobic interaction between $\alpha$-crystallin and the hydrophobic fatty acid core of the membranes, and such interaction is modulated by the PL headgroup's size and charge, hydrogen bonding between headgroups, and PL curvature. Thus, this study provides an in-depth understanding of $\alpha$-crystallin interaction with the PL membranes made of individual and two-component mixtures of the four major PLs of the eye lens membranes.
\end{abstract}

Keywords: $\alpha$-crystallin, phospholipid membranes, binding affinity, physical properties, mobility parameter, maximum splitting, EPR, spin-label. 
This is an author-produced, peer-reviewed version of this article. The final, definitive version of this document can be found online at Experimental Eye Research, published by Elsevier. Copyright restrictions may apply. The content of this document may vary from the final published version. https://doi.org/ 10.1016/j.exer.2020.108337

\section{Introduction}

A cataract is a medical condition in which the eye lens gradually becomes opaque, and vision will be blurred. The causes of cataract include aging (Bron et al., 2000; Truscott, 2005), genetics (Hejtmancik and Kantorow, 2004; Shiels and Hejtmancik, 2007), diabetes (Klein and Klein, 1997; Pollreisz and Schmidt-Erfurth, 2010), hypertension (Leske et al., 1999), obesity (Kuang et al., 2005; Weintraub et al., 2002), corticosteroids and statin medicine to reduce cholesterol (Erie et al., 2016; Lai et al., 2013; Wang et al., 2009), smoking (Solberg et al., 1998), significant alcohol consumption (Gong et al., 2015; Hiratsuka and Li, 2001), eye injury (Khatry et al., 2004; Négrel and Thylefors, 1998), radiation (Jacob, 2013; Lipman et al., 1988; Uwineza et al., 2019), and high myopia (Hoffer, 1993; Ignjatović, 1998; Metge and Donnadieu, 1993). Among these causes, aging is the most common cause of cataract in which the association of $\alpha$-crystallin, a most common lens protein, with the fiber cell plasma membrane of the eye lens increases progressively (Boyle and Takemoto, 1996; Cenedella and Fleschner, 1992; Chandrasekher and Cenedella, 1995; Datiles et al., 2016; Friedrich and Truscott, 2010, 2009; Su et al., 2011). A recent clinical study (Datiles et al., 2016) shows that $\alpha$-crystallin level decreases in the eye lens cytoplasm with age, increasing the level of membrane-bound $\alpha$ crystallin, which increases the light scattering and induces the cataract formation. However, the mechanism by which $\alpha$-crystallin associates with the lens membrane is still unclear.

The three major components of the eye lens membrane are phospholipids (PLs), proteins, and cholesterol. A few studies suggested that $\alpha$-crystallin binds mostly with a lens intercellular junction protein MP26 (Liang and Li, 1992; Mulders et al., 1985). It is also reported that the primary binding sites of $\alpha$-crystallin in the lens membranes are intrinsic PLs (Borchman and Tang, 1996; Chandrasekher and Cenedella, 1997; Ifeanyi and Takemoto, 1991). The observations of amplified interaction of $\alpha$-crystallin with the lens membrane when surface proteins are stripped from the membrane by urea (Cobb and Petrash, 2002a; Ifeanyi and Takemoto, 1989) and trypsin degradation (Cobb and Petrash, 2000) further suggested that the primary binding sites of $\alpha$-crystallin in the lens membrane are PLs. Cholesterol, on the other hand, antagonizes the association of $\alpha$-crystallin to the PL vesicles (Borchman and Tang, 1996; Ifeanyi and Takemoto, 1991; Tang et al., 1998).

Even with many existing studies on $\alpha$-crystallin binding to the lens membranes (Borchman and Tang, 1996; Chandrasekher and Cenedella, 1997; Ifeanyi and Takemoto, 1990a, 1990b, 1989; Mulders et al., 1985; Zhang and Augusteyn, 1994) and PL vesicles (Borchman and Tang, 1996; Cobb and Petrash, 2002b; Ifeanyi and Takemoto, 1991; Tang et al., 1998), the nature of $\alpha$-crystallin interaction with PL membranes is unclear. It is suggested that $\alpha$-crystallin binds deep into the membrane (Tang et al., 1999). Few studies indicated that ionic interactions between $\alpha$-crystallin and PLs influence binding (Mulders et al., 1989, 1985). The studies on $\alpha$-crystallin binding to synthetic lipid membranes (Cobb and Petrash, 2002a; Ifeanyi and Takemoto, 1989; Tang et al., 1998; Tang and Borchman, 1998; Zhang et al., 1999) and bovine lens lipid membranes (Borchman and Tang, 1996; Sato et al., 1996; Tang et al., 1999) suggested that $\alpha$-crystallin binds with lipid membranes noncovalently. A few other studies indicated that the hydrophobic surface of the $\alpha$-crystallin influence binding (Cenedella and Chandrasekher, 1993; Chandrasekher and Cenedella, 1997; Tang et al., 1998). A later study proposed that $\alpha$-crystallin binds to the fiber cell plasma membrane through hydrophobic interactions (Cobb and Petrash, 2000), which occurs between $\alpha$-crystallin and the hydrophobic fatty acid core of the PLs. It is also suggested that membrane and $\alpha$-crystallin interactions are strongly affected by polar PL headgroups (Tsvetkova et al., 2002).

In comparison to the broad interest in the interaction between $\alpha$-crystallin and the intrinsic lens membranes, much less studied is the role of the four major eye lens PLs, i.e., phosphatidylcholine (PC), sphingomyelin (SM), phosphatidylserine (PS), and Phosphatidylethanolamine (PE) (Deeley et al., 2008), in the binding of $\alpha$-crystallin to lens membrane. Moreover, the observations of existing studies on $\alpha$-crystallin binding to individual PL membranes are conflicting. A study performed for individual phosphatidylcholine (PC) with a variety of acyl chain lengths and individual sphingomyelin (SM) membranes suggested that binding of $\alpha$-crystallin to lens membranes is non-saturable and not lipid-specific (Cobb and Petrash, 2002b). They proposed that the surface of the membrane is the only limiting factor, and other differences, such as PL origin, headgroup, and acyl chain length or saturation, do not influence the interaction with the $\alpha$-crystallin. Another study performed for individual SM, PC, and PE revealed that $\alpha$-crystallin binds to these PL membranes in a saturable manner and in a similar amount as with intrinsic lens membranes (Ifeanyi and Takemoto, 1991). In contrast to these studies, a study performed for individual SM and PC membranes reported that a higher amount of $\alpha$-crystallin binds to the SM membrane than to the PC membrane (Tang et al., 1998). An important point to note is that all the previous studies for individual PL membranes reported binding capacity in terms of the amount of $\alpha$-crystallin bound to a certain amount of PLs. With all these, surprisingly, there is no single study 
This is an author-produced, peer-reviewed version of this article. The final, definitive version of this document can be found online at Experimental Eye Research, published by Elsevier. Copyright restrictions may apply. The content of this document may vary from the final published version. https://doi.org/ 10.1016/j.exer.2020.108337

reported earlier for the binding of $\alpha$-crystallin to the individual PS membrane. Also, only a single study (Ifeanyi and Takemoto, 1991) was reported earlier for the binding of $\alpha$-crystallin to the individual PE membrane. The binding of $\alpha$-crystallin with two-component mixtures (SM/PE, SM/PS, and SM/PC) of PL membranes has not been investigated before. Therefore, an explicit study to understand the binding of $\alpha$-crystallin to the PLs of the eye lens membrane is imperative.

The lipid composition in the fiber cell plasma membrane of the eye lens changes dramatically with age and cataract (Borchman, 2020; Borchman et al., 2017; Borchman and Yappert, 2010; Huang et al., 2005; Mainali et al., 2017; Paterson et al., 1997; Truscott, 2000; Yappert et al., 2003) and among species (Borchman, 2020; Borchman et al., 2017; Deeley et al., 2008; Stimmelmayr and Borchman, 2018). With age and cataract, the amount of glycerophospholipids decreases, and sphingolipids increases (Huang et al., 2005). It is reported that the oxidation of glycerophospholipids is the leading cause of changes in lipid composition over age and cataract (Borchman et al., 2017). The oxidative damage in the lens accumulates, which changes the structure of the lens crystallins resulting in light scattering (Borchman et al., 2017). It is possible that the changes in the structure of $\alpha$-crystallin likely triggers its binding with lens membranes. It has been proposed that the binding of $\alpha$-crystallin to the lens membrane serves as a seed for lipid oxidation and binding of other proteins to the membrane, resulting in protein aggregation and light scattering (Tang et al., 1999). Also, with the significant differences in lipid composition among species, the significant differences in the cataract onset age have been observed. For example, PC is dominant in the rat (Deeley et al., 2008), which gets cataract at 2 years (Borchman et al., 2017), and SM is dominant in human (Deeley et al., 2008), which gets cataract at 60 years (Borchman et al., 2017; Stimmelmayr and Borchman, 2018). Whale, which has a dominant amount of sphingolipid (specially dihydrosphingomyelin), does not get cataract until 200 years of age (Borchman et al., 2017; Stimmelmayr and Borchman, 2018). The high amount of dihydrosphingomyelin, which resists to oxidation, and cholesterol (cholesterol/PLs molar ratio of 10:1), which is reported to prevent the association of $\alpha$-crystallin to the PL membranes (Borchman and Tang, 1996; Ifeanyi and Takemoto, 1991; Tang et al., 1998), could inhibit the binding of $\alpha$-crystallin to the lens membranes in whale and protect it from cataract (Borchman et al., 2017; Stimmelmayr and Borchman, 2018). Based on these observations, we speculate that the changes in PL composition with age and among species may contribute to the binding of $\alpha$-crystallin to the membranes, resulting in lens opacity and cataract formation. In this regard, a study of $\alpha$-crystallin binding to the individual and two-component mixtures of PL membranes, providing a clear understanding of the role of changes in PL composition in $\alpha$-crystallin binding with membranes, is significant.

We recently developed the EPR spin-labeling method (Mainali et al., 2020a) to study the interaction of $\alpha$-crystallin with the individual 1-palmitoyl-2-oleoyl-sn-glycero-3-phasphatidylcholine (POPC) membrane. The EPR spinlabeling method has the unique ability to simultaneously provide information about binding affinity and physical properties of the membranes upon binding with $\alpha$-crystallin. In this method, cholesterol analog spin-label CSL incorporated into the membrane monitors the binding of $\alpha$-crystallin to the membrane. The distinguishing aspects of our study (Mainali et al., 2020a) were that, unlike other previous studies for individual PL membranes, we calculated the percentage of membrane surface occupied by the $\alpha$-crystallin and estimated the binding affinity $\left(\mathrm{K}_{\mathrm{a}}\right)$ in terms of inverse micromole $\left(\mu \mathrm{M}^{-1}\right)$ of $\alpha$-crystallin for binding with the membrane. We also calculated the physical properties of the membrane, such as the mobility parameter. The mobility parameter gives the contribution of both the orientational and rotational dynamics of the spin-label in membrane (Schreier et al., 1978). We observed that the mobility parameter decreases with an increase in the binding of $\alpha$-crystallin to the POPC membrane (Mainali et al., 2020a).

In this study, we investigated the binding of $\alpha$-crystallin to individual PL membranes, i.e., SM, 1-palmitoyl-2-oleoyl$s n$-glycero-3-phasphatidylserine (POPS), and 1-palmitoyl-2-oleoyl-sn-glycero-3-phasphoethanolamine (POPE*, where * represents presence of $30 \mathrm{~mol} \%$ of POPC), and the two-component mixture (SM/POPE, SM/POPS, and $\mathrm{SM} / \mathrm{POPC}$ ) of PL membranes. We report the percentage of membrane surface occupied by $\alpha$-crystallin, the binding affinity $\left(\mathrm{K}_{\mathrm{a}}\right.$ ) of $\alpha$-crystallin binding to membranes, and the physical properties (mobility parameter and maximum splitting) of membranes upon binding with $\alpha$-crystallin. The measurements of the percentage of membrane surface occupied and the binding affinity $\left(\mathrm{K}_{\mathrm{a}}\right)$ give information about the percentage of the membrane surface occupied by $\alpha$ crystallin and the strength of $\alpha$-crystallin binding to membrane, respectively. The maximum splitting (a parameter related to order parameter) gives the amplitude of the wobbling motion of the long axes of the CSL spin-label in the membranes (Kusumi et al., 1986; Mainali et al., 2012; Raguz et al., 2011). The results of this study help to identify the PLs in the fiber cell plasma membrane that promote or inhibit the binding of $\alpha$-crystallin to the eye lens membrane. 
This is an author-produced, peer-reviewed version of this article. The final, definitive version of this document can be found online at Experimental Eye Research, published by Elsevier. Copyright restrictions may apply. The content of this document may vary from the final published version. https://doi.org/ 10.1016/j.exer.2020.108337

\section{Materials and Methods}

\section{$\underline{2.1 \text { Materials }}$}

PLs, 1-palmitoy-2-oleoyl-sn-glycero-3-phosphatidylcholine (POPC), 1-palmitoyl-2-oleoyl-sn-glycero-3phosphoethanolamine (POPE), 1-palmitoy-2-oleoyl-sn-glycero-3-phosphatidylserine (POPS), and egg sphingomyelin (SM) were purchased from Avanti Polar Lipids, Inc. (Alabaster, AL, USA). Cholesterol analog cholestane spin-label CSL was purchased from Sigma Aldrich (St. Louis, Mo, USA). Bovine eye lens $\alpha$-crystallin, HEPES, and Sodium Chloride were purchased from Sigma Aldrich (St. Louis, MO, USA). The $\alpha$-crystallin (C4163) obtained from Sigma Aldrich was used without further purification. Based on the information provided by the Sigma Aldrich (i.e., $\alpha \mathrm{A}=$ $19.8 \mathrm{kDa}, \alpha \mathrm{B}=22 \mathrm{kDa}$, and $\alpha \mathrm{A}: \alpha \mathrm{B}=3: 1$ ), the average molecular weight of $\alpha$-crystallin subunit was estimated to be $20.35 \mathrm{kDa}$.

\subsection{Preparation of Small Unilamellar Vesicles (SUVs)}

The PLs and CSL spin-label in chloroform solutions were mixed by maintaining a $1 \mathrm{~mol} \%$ of CSL. The test tube containing the mixtures of PLs and CSL in chloroform were dried by using $\mathrm{N}_{2}$-gas to a final volume $\sim 75 \mu \mathrm{L}$, and then $\sim 400 \mu \mathrm{L}$ of HEPES buffer (10 mM HEPES, $100 \mathrm{mM} \mathrm{NaCl}, \mathrm{pH}=7.4)$ was added to prepare large multilamellar vesicles (LMVs) by using the standard rapid solvent exchange method (RSEM) (Buboltz, 2009; Buboltz and Feigenson, 1999; Huang et al., 1999). The apparatus for RSEM was built in our lab, as described in detail in (Buboltz, 2009). The LMVs were then sonicated using a probe-tip sonicator (Fisher Scientific, Model 550) to obtain the SUVs. Five to ten $10 \mathrm{~s}$ sonication cycles followed by $15 \mathrm{~s}$ cooling in ice were sufficient to transform the milky suspensions of LMVs into transparent solutions of SUVs. The concentration of PLs was maintained to $25 \mathrm{mg} / \mathrm{mL}$. The diameter of the SUVs prepared by sonication is approximately $30 \mathrm{~nm}$ (Mainali et al., 2015).

The SUVs were prepared from individual PLs (SM, POPS, and POPE*) as well as from two-component PL mixtures $\mathrm{SM} / \mathrm{POPC}, \mathrm{SM} / \mathrm{POPS}$, and SM/POPE in 70:30 and 50:50 mol\%. For two-component PL mixtures, SM is mixed with other PLs (i.e., POPC, POPS, and POPE) because SM is the most abundant PL in the human eye lens membrane (Deeley et al., 2008). Fig. 1 shows the structure of PLs (POPC, POPS, SM, and POPE) and CSL spin-label. The locations of the CSL and PLs in Fig. 1 indicate the approximate locations of the CSL in the PL membranes. As seen in Fig. 1, the nitroxide moiety of CSL spin-label resides near the headgroup region of PLs. Because of the negative curvature of the POPE molecule, the individual POPE membrane could not assemble into the lamellar phase (Hamai et al., 2006). Instead, the POPE membrane might favor the hexagonal phase (Tate et al., 1991), in which headgroups face towards center and tails spread out. Therefore, as stated in (Sendecki et al., 2017), the POPE* membrane was made by the mixture of $70 \mathrm{~mol} \%$ POPE and $30 \mathrm{~mol} \%$ POPC.

\section{$\underline{\text { 2.3 Interaction Between } \alpha \text {-Crystallin and Membranes }}$}

The SUVs at a fixed PL concentration of $9.4 \mathrm{mM}$ were mixed with varying concentrations of $\alpha$-crystallin $(0-52.6$ $\mu \mathrm{M})$ in the total volume of $70 \mu \mathrm{L}$ and incubated at $37^{\circ} \mathrm{C}$ for $16 \mathrm{hr}$ with gentle shaking in a Corning LSE benchtop shaking incubator (Corning, NY, USA). As evident from our recent study (Mainali et al., 2020a), the binding of $\alpha$ crystallin increases with incubation time and saturates at $\sim 8 \mathrm{hr}$.

Native $\alpha$-crystallin brought from Sigma-Aldrich might not be completely pure. As stated in our previous study (Mainali et al., 2020a), it is estimated that the isolation of $\alpha$-crystallin from the bovine eye lens consists of $\sim 6 \%$ other lens proteins (Horwitz et al., 1998; Ryazantsev et al., 2018). So, there is a possibility that other lens proteins may bind with the membranes. Since $\alpha$-crystallin is the most abundant fraction ( $94 \%)$, we suggest that the change in the organization and dynamics of the membranes sensed by the CSL spin-labels in the membranes is most likely due to $\alpha$-crystallin. Previously, Cobb and Petrash (Cobb and Petrash, 2002b) used both the native and recombinant bovine $\alpha$ crystallin for the binding experiments with synthetic PC 16:0 vesicles and did not observe significant differences between native bovine $\alpha$-crystallin binding with the vesicles compared to the recombinant $\alpha$-crystallin binding with vesicles.

The three classes of crystallins, $\alpha-, \beta$-, and $\gamma$-crystallin, account for nearly $90 \%$ of the lens proteins (Horwitz, 2003; Horwitz et al., 1999; Santhoshkumar et al., 2011). Among them, $\alpha$-crystallin comprises up to $40 \%$ of the total lens proteins (Horwitz et al., 1999) and has the strongest affinity to lens membranes (Boyle and Takemoto, 1996; Cenedella and Fleschner, 1992; Chandrasekher and Cenedella, 1997; Cobb and Petrash, 2000; Grami et al., 2005; Tang et al., 
This is an author-produced, peer-reviewed version of this article. The final, definitive version of this document can be found online at Experimental Eye Research, published by Elsevier. Copyright restrictions may apply. The content of this document may vary from the final published version. https://doi.org/ 10.1016/j.exer.2020.108337

1998). It has also been reported that $\alpha$ - and $\beta$-, but not $\gamma$-, crystallins modulate the headgroup order of the human eye lens membranes during aging (Zhu et al., 2010). Based on these studies, we think that $\alpha$-crystallin (used in this study), along with $\beta$-crystallin, binds with the membrane PLs. Several studies indicated that with age and cataract formation, the level of $\alpha$-crystallin in the lens cytoplasm decreases, and the amount of membrane-bound $\alpha$-crystallin increases (Chandrasekher and Cenedella, 1995; Datiles et al., 2016; Su et al., 2011). A clinical study also shows that the level of the unbound form of $\alpha$-crystallin decreases with cataract progression (Datiles et al., 2016). Instead of the various reports of $\alpha$-crystallin binding to lens plasma membranes, the clear understanding of $\alpha$-crystallin interaction with the four major PLs of the eye lens membranes is lacking. Moreover, binding of $\alpha$-crystallin to two-component mixtures of these PLs has not been studied before. These are the reasons we choose $\alpha$-crystallin over the other crystallins ( $\beta$-, and $\gamma$-crystallin) to test in our system.

Bovine eye lens $\alpha$-crystallin consists of $\alpha \mathrm{A}$ and $\alpha \mathrm{B}$ subunits in a 3:1 molar ratio (Horwitz et al., 1999). $\alpha$-crystallin remains in the form of highly polydisperse oligomers (Horwitz et al., 1998; Ryazantsev et al., 2018), and its subunits exchange between oligomers (Bova et al., 2000, 1997; Ryazantsev et al., 2018; Van den Oetelaar et al., 1990). A differential scanning calorimetry study (Srinivas et al., 2010) reported that both the $\alpha$-crystallin heteropolymer in 3:1 molar ratio and $\alpha \mathrm{A}$-crystallin homopolymer does not precipitate below their unfolding temperature between $58-61$ ${ }^{\circ} \mathrm{C}$. Based on these observations, it is likely that $\alpha$-crystallin is stable at $37^{\circ} \mathrm{C}$ for $16 \mathrm{hr}$. Also, for SUVs prepared with different PLs (individual and two-component mixtures), we did not find significant differences in EPR signals measured for $0 \mathrm{hr}$ and $16 \mathrm{hr}$ incubated samples indicating the stability of SUVs (see Section 2.4. for EPR measurements).

\section{$\underline{\text { 2.4 EPR Measurements }}$}

The incubated samples were transferred to a $0.6 \mathrm{~mm}$ i.d. capillary made of gas-permeable methylpentene polymer (TPX) (Subczynski et al., 2005) for continuous-wave (CW) EPR measurements. The EPR spectra were recorded with an X-band Brucker ELEXSYS 500 spectrometer connected with the accessories to control the temperature. Samples were thoroughly deoxygenated before performing EPR measurements. The EPR spectra were collected at $37^{\circ} \mathrm{C}$ with a modulation amplitude of $1.0 \mathrm{G}$ and incident microwave power of $5.0 \mathrm{~mW}$. All spectra for a single series of a sample were collected in a single day.

\subsection{Measurements of Binding Affinity}

After the EPR measurements, each spectrum was normalized with respect to peak to peak intensity of the central EPR line. The representative normalized EPR spectra for the SM membrane without $\alpha$-crystallin (black) and with $52.6 \mu \mathrm{M}$ $\alpha$-crystallin (red) are shown in Fig. 2A. Fig. 2B (the zoomed low field EPR lines of the spectra in Fig. 2A) illustrates that the low field EPR line's peak to peak signal intensity decreases when $\alpha$-crystallin binds to the SM membrane. Previously, we have observed a similar decrease in the low field EPR line's peak to peak signal intensity when $\alpha$ crystallin binds to the POPC membrane (Mainali et al., 2020a). The ratio of peak to peak signal intensities of the low field and the central field EPR line of the CSL spin-label in the membrane gives the mobility parameter (Mainali et al., 2020a, 2012; Raguz et al., 2011). Herein, we use the change in peak to peak signal intensity of the low field EPR line to calculate the binding affinity.

The method developed to estimate the binding affinity $\left(\mathrm{K}_{\mathrm{a}}\right)$ of $\alpha$-crystallin to the POPC membrane using the EPR spinlabeling approach is explained in our recent study (Mainali et al., 2020a). In this study, we use this recently developed method to estimate the $\mathrm{K}_{\mathrm{a}}$ of $\alpha$-crystallin binding to the individual (SM, POPS, and POPE*) and two-component (SM/POPE, SM/POPS, and SM/POPC) mixtures of PL membranes. The EPR spectra without $\alpha$-crystallin were used as a control representing the unbound contribution $\left(\mathrm{U}_{0}\right)$, and the EPR spectra at different $\alpha$-crystallin concentrations were used as unbound plus bound contributions $\left(\mathrm{U}_{0}+\mathrm{B}_{0}\right)$ (see Fig. 2B). As $\alpha$-crystallin binds near the outer membrane surface, the percentage of the CSL spin-labels affected due to the binding of $\alpha$-crystallin is estimated as (Mainali et al., 2020a):

$$
\% \text { CSL spin-label affected }=\left\{\frac{\mathrm{U}_{0}-\left(\mathrm{U}_{0}+\mathrm{B}_{0}\right)}{\mathrm{U}_{0}}\right\} 100 \%
$$


This is an author-produced, peer-reviewed version of this article. The final, definitive version of this document can be found online at Experimental Eye Research, published by Elsevier. Copyright restrictions may apply. The content of this document may vary from the final published version. https://doi.org/ 10.1016/j.exer.2020.108337

As our membranes are SUVs with $\sim 30 \mathrm{~nm}$ diameter (Mainali et al., 2015), $\sim 60 \%$ of the CSL molecules are near the outer surface of the membrane, and $\sim 40 \%$ of the CSL molecules are near the membrane's inner surface. Only the CSL molecules near the outer surface of the membrane are affected by the binding of $\alpha$-crystallin. Therefore, the corrected percentage of CSL spin-labels affected or the percentage of outer membrane surface occupied by $\alpha$-crystallin is calculated by multiplying equation (1) by the correction factor $\left(\frac{100}{60}\right)$ :

$$
\% \text { membrane surface occupied }=\% \text { CSL spin-label affected }\left(\frac{100}{60}\right)
$$

The calculated percentages of the membrane surface occupied by the $\alpha$-crystallin were plotted as a function of the $\alpha$ crystallin concentration. The data points were then fitted using GraphPad Prism (San Diego, CA) with a one-site ligand binding model:

$$
\mathrm{Y}=\frac{\mathrm{X} B_{\max }}{\mathrm{K}_{\mathrm{d}}+\mathrm{X}}
$$

where $\mathrm{B}_{\max }$ is the maximum specific binding in the same unit as $\mathrm{Y}$ and $\mathrm{K}_{\mathrm{d}}$ (dissociation constant) is the equilibrium binding constant in the same unit as $\mathrm{X}$. In our experimental conditions, $\mathrm{B}_{\max }$ is the extrapolation of the percentage of the membrane surface occupied by a very high concentration of $\alpha$-crystallin, and $K_{d}$ is the $\alpha$-crystallin concentration needed to achieve a half-maximum binding at equilibrium. All the membrane surface regions are identical, and $\alpha-$ crystallin can bind to any region of the membrane's outer surface with equal probability. Thus, we have used the onesite ligand binding model to estimate the binding constant $\mathrm{K}_{\mathrm{d}}$. We, along with others, have previously used the onesite ligand binding model to estimate the binding affinity (Mainali et al., 2020a; Schultz et al., 2017, 2013). The association constant $\left(\mathrm{K}_{\mathrm{a}}\right)$ is calculated by using:

$$
\mathrm{K}_{\mathrm{a}}=\frac{1}{\mathrm{~K}_{\mathrm{d}}}
$$

Here, $K_{a}$ gives information about how strongly $\alpha$-crystallin binds to the membranes. The higher the value of $K_{a}$, the stronger is the binding and vice-versa.

The percentage of membrane surface occupied and the $\mathrm{K}_{\mathrm{a}}$ provide distinct meaning here. The percentage of membrane surface occupied gives quantitative information about how much of the membrane surface is occupied by $\alpha$-crystallin. On the other hand, the $K_{a}$ provides quantitative information about how quickly the maximum surface occupied is achieved. If there is no binding of $\alpha$-crystallin to the membrane, the values of both the percentage of membrane surface occupied and $\mathrm{K}_{\mathrm{a}}$ become zero. But if there is a binding of $\alpha$-crystallin to the membrane, the value of $\mathrm{K}_{\mathrm{a}}$ depends on how quickly the percentage of membrane surface occupied increases. For the same maximum percentage of membrane surface occupied, we may have multiple values of $\mathrm{K}_{\mathrm{a}}$ depending on how fast the binding saturation is achieved.

The protocol from Avanti Polar Lipids (Burgess, 1998) mentions that the probe tip sonication produces SUVs with diameters in the range of $15-50 \mathrm{~nm}$. Based on this information, we have taken $\sim 30 \mathrm{~nm}$ for the size of vesicles in our calculations. The percentage of membrane surface occupied by $\alpha$-crystallin depends upon the number of $\alpha$-crystallin molecules bound on the outer membrane surface, which are sensed by the CSL spin-labels on the outer surface of the membrane. Even if the vesicle is larger or smaller, we expect no significant difference in the percentage of membrane surface occupied by $\alpha$-crystallin. The percentage of CSL molecules on the outer surface of the larger vesicle is smaller compared to the smaller vesicle. However, the decrease in the percentage of the CSL spin-labels affected in a larger vesicle, as estimated by equation 1 , is compensated by multiplying with a larger correction factor in equation 2 . That would lead to no significant difference in the membrane surface occupied by $\alpha$-crystallin between larger and smaller vesicles. For example, for a $200 \mathrm{~nm}$ diameter vesicle, $\sim 52 \%$ of the CSL molecules are near the outer surface, which is smaller than in $\sim 30 \mathrm{~nm}$ vesicle, where $\sim 60 \%$ of the CSL molecules are near the outer surface. The decreases in the percentage of CSL spin-labels affected in $200 \mathrm{~nm}$ vesicle is compensated by multiplying with larger correlation factor (i.e., $100 / 52$ in $200 \mathrm{~nm}$ vesicle compared to $100 / 60$ in $30 \mathrm{~nm}$ vesicle) in equation 2 , that would lead to no significant difference in the membrane surface occupied by $\alpha$-crystallin between $30 \mathrm{~nm}$ and $200 \mathrm{~nm}$ vesicles. Therefore, we speculate that the results obtained in this study for SUVs may likely be valid in the case of lens fiber with $2 \times 10 \mu \mathrm{m}$ cross-section (Bassnett and Costello, 2017). We plan to investigate the $\alpha$-crystallin binding to smaller vs. larger vesicles in detail in our next projects. 
This is an author-produced, peer-reviewed version of this article. The final, definitive version of this document can be found online at Experimental Eye Research, published by Elsevier. Copyright restrictions may apply. The content of this document may vary from the final published version. https://doi.org/ 10.1016/j.exer.2020.108337

\subsection{Measurements of Physical Properties of Membranes}

The measured physical properties are the mobility parameter and maximum splitting of the membranes after binding with $\alpha$-crystallin. The mobility parameter gives the orientational and rotational mobility of the CSL molecules in the membranes (Schreier et al., 1978). The maximum splitting is a parameter related to the order parameter that gives the amplitude of the wobbling motion of the long axes of the CSL spin-label in the membranes (Kusumi et al., 1986; Mainali et al., 2012; Raguz et al., 2011). Since CSL spin-labels are on both the membrane's inner and outer surfaces, the mobility parameter and maximum splitting give the average effect of CSL spin-labels contributing from both surfaces of the membrane. As explained in our previous studies (Mainali et al., 2012; Raguz et al., 2011), the ratio of peak to peak intensity of the low field and the central field EPR line (i.e., $h_{+} / h_{0}$ ) gives the mobility parameter (see Fig. 2A), and the horizontal distance between the low field and high field EPR lines gives the maximum splitting (see Fig. 2C).

\subsection{Statistics}

The Student's t-test was used to determine the statistical significance between the maximum percentages of membrane surface occupied and the binding affinities $\left(\mathrm{K}_{\mathrm{a}}\right)$. For the maximum percentages of membrane surface occupied, we used the values obtained after the binding saturation. For the binding affinities $\left(K_{a}\right)$, we used the $K_{a}$ values obtained from three independent experiments. The statistical significance was determined by comparing the values (either the maximum percentages of membrane surface occupied or the binding affinities) among each other for different membranes. For individual membranes, POPC was compared with the POPS and SM, and the POPS was compared with the SM. For two-component membranes, SM/POPC was compared with the SM/POPS and SM/POPE, and the SM/POPS was compared with the SM/POPE. A value of $p \leq 0.05$ was considered statistically significant.

\section{Results and Discussion}

\section{$\underline{3.1 K_{\mathrm{a}} \text { of } \alpha \text {-Crystallin to Individual PI Membranes }}$}

The PL membrane SM or POPS or POPE* and $\alpha$-crystallin in HEPES buffer (10 mM HEPES and $100 \mathrm{mM} \mathrm{NaCl}$ at $\mathrm{pH}$ 7.4) were incubated for $16 \mathrm{hr}$ at $37^{\circ} \mathrm{C}$ with gentle shaking, and EPR measurements were performed at $37^{\circ} \mathrm{C}$. The concentration of the PL membrane was fixed at $9.4 \mathrm{mM}$, and the concentration of $\alpha$-crystallin was varied $(0-52.6$ $\mu \mathrm{M})$. Representative EPR spectra recorded for individual PL membranes are shown in Fig. 2. Fig. 2A, 2C, and 2E show the representative EPR spectra for SM, POPS, and POPE* in the absence of $\alpha$-crystallin (black), and $52.6 \mu \mathrm{M}$ $\alpha$-crystallin (red), respectively. The zoomed low field EPR lines of the spectra for SM, POPS, and POPE* membranes are shown in Fig. 2B, 2D, and 2F, respectively. Each of the EPR spectra were normalized with respect to peak to peak intensity of the central EPR line. Fig. 2B and 2D show that low field line's peak to peak intensity for SM and POPS membranes decreases in the presence of $\alpha$-crystallin. Such a decrease in the intensity is attributed to the binding of $\alpha$ crystallin to the membranes. There is no decrease in the peak to peak intensity in the low field EPR line of the POPE* membrane in the presence of $\alpha$-crystallin, as shown in Fig. $2 \mathrm{~F}$. It represents that there is no binding of $\alpha$-crystallin to the POPE* membrane.

The binding affinity $\left(\mathrm{K}_{\mathrm{a}}\right)$ of $\alpha$-crystallin to PL membranes was computed by using the method explained in section 2.5. Fig. 3A shows the percentage of membrane surface occupied by $\alpha$-crystallin plotted as a function of $\alpha$-crystallin concentration for POPE*, POPS, SM, and POPC membranes. The data for the POPC membrane was taken from our previous study (Mainali et al., 2020a). In Fig. 3A, the solid lines represent the fitted curves using the one-site ligand binding model (using equation 3 ). With an increase in the $\alpha$-crystallin concentration, the percentage of membrane surface occupied increases initially and then saturates for POPS, SM, and POPC membranes (Fig. 3A). For the POPE* membrane, the percentage of membrane surface occupied is zero for all concentrations of $\alpha$-crystallin (Fig. 3A). These data imply that there was a binding of $\alpha$-crystallin to the POPS, SM, and POPC membranes, but not to the POPE* membrane. The maximum surface occupied by $\alpha$-crystallin to POPS, SM, and POPC membranes was found to be $\sim 11 \%, \sim 14 \%$, and $\sim 10 \%$, respectively. It shows that a higher amount of $\alpha$-crystallin binds to the SM membrane than to POPS and POPC membranes. The amount of $\alpha$-crystallin binding with the POPS and POPC membranes are almost equal. Statistically significant differences were seen with $\mathrm{p} \leq 0.05$ when the maximum percentages of membrane surface occupied by $\alpha$-crystallin on individual PL membranes were compared among each other. Our results are in agreement with the previous study that reported a higher amount of $\alpha$-crystallin binds with the SM membrane than with PC membrane (Tang et al., 1998). To the best of our knowledge, we are the first to estimate the membrane surface 
This is an author-produced, peer-reviewed version of this article. The final, definitive version of this document can be found online at Experimental Eye Research, published by Elsevier. Copyright restrictions may apply. The content of this document may vary from the final published version. https://doi.org/ 10.1016/j.exer.2020.108337

occupied by the $\alpha$-crystallin. Previously, Mulders (Mulders et al., 1985) labeled $\alpha$-crystallin with $\left[{ }^{35} \mathrm{~S}\right]$ methionine and incubated with various concentrations of the egg yolk lecithin vesicles (phosphatidylcholine vesicles) and found $\sim 10 \%$ $\alpha$-crystallin bound to the vesicles.

Fig. 3B shows the bar plot of the $\mathrm{K}_{\mathrm{a}}$ of $\alpha$-crystallin binding to individual PL membranes. The estimated $\mathrm{K}_{\mathrm{a}}$ of $\alpha$ crystallin binding to POPE*, POPS, SM, and POPC membranes are 0, 0.25 $\pm 0.1,1.49 \pm 0.77$, and $4.9 \pm 2.4 \mu \mathrm{M}^{-1}$, respectively. Statistically significant differences were seen with $\mathrm{p} \leq 0.05$ when the $\mathrm{K}_{\mathrm{a}}$ values of $\alpha$-crystallin binding on individual PL membranes were compared among each other. The estimated $\mathrm{K}_{\mathrm{a}}$ of $\alpha$-crystallin to POPC membranes was taken from our earlier work (Mainali et al., 2020a). The errors in the value of $\mathrm{K}_{\mathrm{a}}$ were estimated from the $95 \%$ confidence interval (profile likelihood) from the one-site ligand binding model. The higher value of $K_{a}$ indicates the tighter binding of $\alpha$-crystallin to the membranes, whereas the lower value of $K_{a}$ indicates the weaker binding of $\alpha$ crystallin to membranes. These results show that POPE* inhibits the binding of $\alpha$-crystallin the most (no binding observed), whereas POPC inhibits binding the least. Previously, Mulders (Mulders et al., 1985) labeled $\alpha$-crystallin with $\left[{ }^{35} \mathrm{~S}\right]$ methionine and estimated the $\mathrm{K}_{\mathrm{a}}$ of $7.69 \mu \mathrm{M}^{-1}$ for $\alpha$-crystallin binding to the alkali-washed lens plasma membrane.

The PL membranes used in this study do not include intrinsic membrane proteins, which might consist of hydrophobic regions. It has been reported earlier (Mulders et al., 1985; Reddy et al., 2006) that $\alpha$-crystallin contains hydrophobic regions on its surface. Our data suggest that the binding of $\alpha$-crystallin to membranes is likely due to the hydrophobic interactions involving the hydrophobic fatty acid core of the membrane bilayer and hydrophobic regions of the $\alpha$ crystallin. Since the binding of $\alpha$-crystallin to PL membranes with the same hydrophobic fatty acid core (i.e., POPE*, POPS, and POPC) has different $\mathrm{K}_{\mathrm{a}}$ (Fig. 3), we think that the hydrophobic interactions are mediated by the PL headgroup's charge and size, hydrogen bonding between headgroups, and PL curvature. Previously, it was reported that the binding of $\alpha$-crystallin to protein-free membranes depends on the hydrocarbon chain order (Tang et al., 1998). It was also reported that the interaction between $\alpha$-crystallin and fiber cell plasma membrane was hydrophobic in nature (Cobb and Petrash, 2000). Moreover, the infrared spectroscopy measurements (Tsvetkova et al., 2002) suggested that the polar headgroup regions of lipid mediate interactions between $\alpha$-crystallin and lipid membranes.

The $\mathrm{K}_{\mathrm{a}}$ of $\alpha$-crystallin to individual PL membranes followed the trends: $\mathrm{K}_{\mathrm{a}}(\mathrm{POPC})>\mathrm{K}_{\mathrm{a}}(\mathrm{SM})>\mathrm{K}_{\mathrm{a}}(\mathrm{POPS})>$ $\mathrm{K}_{\mathrm{a}}\left(\right.$ POPE* $^{*}$ (Fig. 3B). The $\mathrm{K}_{\mathrm{a}}$ of $\alpha$-crystallin to SM membrane is about three times smaller than the $\mathrm{K}_{\mathrm{a}}$ of $\alpha$-crystallin to POPC membrane; whereas, the $K_{a}$ of $\alpha$-crystallin to SM membrane is about six times larger than the $K_{a}$ of $\alpha$ crystallin to POPS membrane. These significant differences in the $\mathrm{K}_{\mathrm{a}}$ of $\alpha$-crystallin to major eye lens PL membranes might result from the different PL headgroup's ability to interact with one another at the bilayer/water interface. The POPC headgroup has only a hydrogen bond (H-bond) acceptor group (Mainali et al., 2020b; Nylund et al., 2006; Saito et al., 2018). The headgroup of POPS, POPE, and SM have both H-bond donor and acceptor groups (Mainali et al., 2020b; Nylund et al., 2006; Saito et al., 2018; Slater et al., 1993), so they potentially make inter-lipid H-bonds at the bilayer/water interface. The POPE headgroup is smaller in size than those of the other PLs, i.e., $38 \AA^{2}$ PE headgroup compared with $50 \AA^{2}$ for PC headgroup (Hauser et al., 1981), and the POPE headgroup can interact with one another via hydrogen bonding (Casal and Mantsch, 1984; Slater et al., 1993). So, the packing of the lipids in the POPE* bilayer is dense, which significantly reduces the hydrophobic interaction between $\alpha$-crystallin and the hydrophobic fatty acid core of the bilayer. As a result, the POPE* inhibits the binding the most compared with the other three PLs. Due to the negative curvature of the POPE molecules (Hamai et al., 2006), when they assemble to form the individual POPE vesicles in solution, they form the inverted micelles in which the headgroups face towards the center and tails spread out (Tate et al., 1991). The reason why PE is not an effective binding of $\alpha$-crystallin may be that it forms inverted micelles where the headgroups are buried inside the micelles. Since POPC does not form inter-lipid H-bonds at the bilayer/water interface due to the presence of the H-bond acceptor group only, this greatly increases hydrophobic interactions between $\alpha$-crystallin and the hydrophobic fatty acid core of the POPC bilayer. As a result, the POPC inhibits binding the least in comparison with the other three PLs. The H-bonds donor groups of an SM molecule are below the phosphate group (Saito et al., 2018; Slotte, 2016), so they are not easily accessible to acceptor groups of other SM molecules. So, inter-lipid H-bonds are possible but not frequent in SM bilayer in contrast to POPE-POPE H-bonds. Therefore, SM has smaller $\mathrm{K}_{\mathrm{a}}$ than POPC. The POPS molecule has a net negative electrostatic charge. So, the POPS headgroups repel one another, and H-bonds practically do not form. The net negative electrostatic charge on the POPS bilayer surface (Boyle and Takemoto, 1996; Cenedella and Fleschner, 1992) significantly reduces hydrophobic interaction between the $\alpha$-crystallin and hydrophobic fatty acid core of the POPS bilayer. As a result, the $\mathrm{K}_{\mathrm{a}}$ of $\alpha$-crystallin to POPS membrane is significantly lower than the $\mathrm{K}_{\mathrm{a}}$ of $\alpha$-crystallin to SM and POPC membranes. 
This is an author-produced, peer-reviewed version of this article. The final, definitive version of this document can be found online at Experimental Eye Research, published by Elsevier. Copyright restrictions may apply. The content of this document may vary from the final published version. https://doi.org/ 10.1016/j.exer.2020.108337

\subsection{Physical Properties of Individual PL Membranes After Binding with a-Crystallin}

Besides $K_{a}$, the mobility parameter and the maximum splitting of membranes after binding with $\alpha$-crystallin were measured by using the method explained in section 2.6. Fig. 4A shows the mobility parameter plotted as a function of $\alpha$-crystallin concentration for individual PL membranes. The data for the POPC membrane was taken from our previous study (Mainali et al., 2020a). Without $\alpha$-crystallin (at $0 \mu \mathrm{M} \alpha$-crystallin), the mobility parameter of individual PL membranes followed the trends: POPC $>$ POPS $>$ POPE* $>$ SM. Fig. 4A shows that the mobility parameter decreases with an increase in $\alpha$-crystallin concentration for SM, POPS, and POPC membranes, whereas for POPE* membrane the mobility parameter does not change with the increase in $\alpha$-crystallin concentration. The results indicate that the headgroup regions of the POPC, SM, and POPS membranes become less mobile due to the binding of $\alpha$ crystallin to these membranes. There is no change in POPE* membrane's mobility parameter because of no binding of $\alpha$-crystallin to this membrane, or the binding is very weak or not detected. Previously, using the fluorophore NBDPE, which partitions near the membrane headgroup region, Borchman and Tang (Borchman and Tang, 1996) found a similar decrease in mobility of the headgroups of bovine lens lipid vesicles upon binding with $\alpha$-crystallin.

Fig. 4B shows the maximum splitting for the four individual PL (POPE*, POPS, SM, and POPC) membranes plotted as a function of $\alpha$-crystallin concentration. For the SM membrane, maximum splitting increases with an increase in $\alpha$ crystallin concentration and saturates at $\sim 10 \mu \mathrm{M} \alpha$-crystallin concentration. It implies that the SM membrane becomes more ordered when more and more $\alpha$-crystallin binds to it. Surprisingly, no change in maximum splitting for POPC and POPS membranes was observed with an increase in $\alpha$-crystallin concentration (Fig. 4B). It implies that the order of these membranes did not change when more and more $\alpha$-crystallin was bound to POPC and POPS membranes. Since $\alpha$-crystallin did not bind with POPE* membrane, there was no surprise that maximum splitting remained the same for the POPE* membrane with an increase in $\alpha$-crystallin concentration. Without $\alpha$-crystallin (at $0 \mu \mathrm{M} \alpha-$ crystallin), the maximum splitting of individual PL membranes followed the trends: SM $>$ POPS $\approx$ POPE* $>$ POPC. With aging, an increase in the amount of SM and a decrease in the amount of PC is expected (Borchman et al., 1994; Yappert et al., 2003). Our observations that the highest maximum splitting for SM and lowest maximum splitting for POPC support the observation of increased order (stiffness) of the lens lipids (Borchman et al., 2004, 1999) with aging.

\section{$\underline{3.3 K_{\mathrm{a}} \text { of } \alpha \text {-Crystallin to Two-Component Mixtures of PL Membranes }}$}

The fixed concentration $(9.4 \mathrm{mM}$ ) of two-component mixtures of PL membrane (SM/POPC or SM/POPE or SM/POPS in 70:30 mol\% and 50:50 mol\%) was mixed with different concentrations of $\alpha$-crystallin $(0-52.6 \mu \mathrm{M})$ in HEPES buffer and incubated for $16 \mathrm{hr}$ at $37^{\circ} \mathrm{C}$ with gentle shaking. After incubation of the samples, EPR measurements were performed at $37{ }^{\circ} \mathrm{C}$. The representative EPR spectra for two-component mixtures of PL membranes in 70:30 mol\% without $\alpha$-crystallin (black) and with $52.6 \mu \mathrm{M} \alpha$-crystallin (red) are shown in Fig. 5. The spectra for SM/POPS, $\mathrm{SM} / \mathrm{POPE}$, and SM/POPC, all in 70:30 mol\%, are shown in Fig. 5A, 5C, and 5E, respectively. The zoomed low field line of EPR spectra in Fig. 5A, 5C, and 5E are shown in Fig. 5B, 5D, and 5F, respectively. The spectra for all the samples were normalized with respect to the central line of the respective EPR spectra. The decrease in peak to peak intensity of the low field EPR line was observed for all the two-component PL membranes due to the binding of $\alpha$ crystallin to the membranes (Fig. 5).

The $\mathrm{K}_{\mathrm{a}}$ of $\alpha$-crystallin to two-component mixtures of PL membranes was calculated by using the method explained in section 2.5. Fig. 6A and $6 \mathrm{C}$ show the percentage of membrane surface occupied by the $\alpha$-crystallin plotted as a function of $\alpha$-crystallin concentration for SM/POPC, SM/POPS, and SM/POPE in 70:30 mol $\%$ and 50:50 mol $\%$, respectively. The solid lines in these plots represent the curves fitted with a one-site ligand binding model (using equation 3). Similar to the individual PL membranes (i.e., POPS, SM, and POPC), the binding of $\alpha$-crystallin to all two-component mixtures of PL membranes is saturated. These observations show similarity to previous reports (Borchman and Tang, 1996; Ifeanyi and Takemoto, 1991; Tang and Borchman, 1998), which suggested the saturable binding of $\alpha$-crystallin to protein-free PL vesicles. The maximum percentage of membrane surface occupied by $\alpha$-crystallin for SM/POPE, SM/POPS, and SM/POPC membranes in $70: 30 \mathrm{~mol} \%$ was $\sim 13 \%, \sim 10 \%$, and $\sim 8 \%$, respectively. Statistically significant differences were seen with $\mathrm{p} \leq 0.05$ when the maximum percentages of membrane surface occupied by $\alpha$ crystallin on two-component PL membranes in 70:30 mol\% were compared among each other. For PL mixtures in 50:50 mol\%, the maximum percentage of membrane surface occupied by $\alpha$-crystallin for both the SM/POPC and $\mathrm{SM} / \mathrm{POPS}$ was $\sim 8 \%$, and for SM/POPE was $\sim 2 \%$. When the maximum percentages of membrane surface occupied by $\alpha$-crystallin on two-component PL membranes in $50: 50 \mathrm{~mol} \%$ were compared among each other, statistically 
This is an author-produced, peer-reviewed version of this article. The final, definitive version of this document can be found online at Experimental Eye Research, published by Elsevier. Copyright restrictions may apply. The content of this document may vary from the final published version. https://doi.org/ 10.1016/j.exer.2020.108337

significant differences with $\mathrm{p} \leq 0.05$ were observed between SM/POPE and SM/POPC, and SM/POPE and SM/POPS; however, no significant difference with $\mathrm{p} \leq 0.05$ was observed between SM/POPC and SM/POPS. Surprisingly for $\mathrm{SM} / \mathrm{POPE}(50: 50 \mathrm{~mol} \%)$, the maximum percentage of membrane surface occupied is $\sim 2 \%$, which is significantly lower than for other PL mixtures. These values of maximum percentage of membrane surface occupied by $\alpha$-crystallin (except for SM/POPE in 50:50 mol\%) on two-component mixtures of PL membranes are comparable to the maximum percentage of membrane surface occupied by $\alpha$-crystallin on individual PL membranes (see Fig. 3A). Since the outer membrane surface is identical throughout the vesicle, $\alpha$-crystallin can bind to any region of the outer membrane surface with equal probability. If the binding of $\alpha$-crystallin was specific to some membrane regions, then the binding would saturate at a very low concentration of $\alpha$-crystallin. However, our data (Figs. 3 and 6 ) show that the saturable binding is observed at a high concentration of the $\alpha$-crystallin. Therefore, we think that the binding of $\alpha$-crystallin to membranes is non-specific. As the maximum percentage of membrane surface occupied by $\alpha$-crystallin on all the membrane surfaces (both individual and two-component mixtures) is small, we speculate that small oligomers of $\alpha$ crystallin participate in binding with the membranes. The steric hindrance between the bound oligomers may also contribute to the smaller membrane surface occupied by $\alpha$-crystallin. Also, it has been reported earlier that $\alpha$-crystallin has hydrophobic regions on its surface (Mulders et al., 1985; Reddy et al., 2006). Our data (see Section 3.1 and the last two paragraphs in Section 3.3) suggest that likely hydrophobic interaction occurs between $\alpha$-crystallin and PL membranes. Previously, Petrash et al., (Cobb and Petrash, 2000) suggested that $\alpha$-crystallin interacts with the lens membrane via hydrophobic interaction. Based on these observations, it may be likely that only $\alpha$-crystallin surface with hydrophobic regions (not the whole $\alpha$-crystallin) contributes to the membrane surface occupied, resulting in the smaller percentage of membrane surface occupied (see Fig. 3A, 6A, and 6C). The CSL spin-label present close to the membrane surface may be affected only by the hydrophobic regions on the surface of $\alpha$-crystallin. Therefore, the possibility of larger oligomers of $\alpha$-crystallin binding to the membranes, with only hydrophobic regions present on the surface of the $\alpha$-crystallin participating for binding, cannot be discarded.

PL composition in the eye lens membranes changes significantly with age and cataract (Huang et al., 2005; Mainali et al., 2017; Paterson et al., 1997; Truscott, 2000; Yappert et al., 2003) as well as in between species (Borchman et al., 2004; Deeley et al., 2008). It has also been reported that the binding of $\alpha$-crystallin with lens membranes increases with age and cataract (Boyle and Takemoto, 1996; Cenedella and Fleschner, 1992; Chandrasekher and Cenedella, 1995; Datiles et al., 2016; Friedrich and Truscott, 2010; Su et al., 2011). Our data (Figs. 3 and 6) show that the binding of $\alpha$-crystallin changes significantly between the individual (PE*, PS, PC, and SM) and between two-component mixtures of PL membranes, suggesting that the PL composition plays a significant role in modulating the binding of $\alpha$-crystallin to membranes. Based on these observations, we hypothesize that the changes in PL composition can be the translocation event that promotes $\alpha$-crystallin translocation from the lens cytoplasm to the membrane. Also, it has been reported that $\alpha$-crystallin denatures by modifications, such as post-translational modifications (Lampi et al., 1998; Shih et al., 1998), and binds to the membranes (Cobb and Petrash, 2002b; Tang et al., 1999). Therefore, $\alpha$-crystallin modifications may also be a translocation event that promotes $\alpha$-crystallin translocation from the lens cytoplasm to the membrane.

Fig. 6B and 6D show the bar plot of the $\mathrm{K}_{\mathrm{a}}$ of $\alpha$-crystallin binding to two-component mixtures of PL membranes in $70: 30 \mathrm{~mol} \%$ and 50:50 mol\%, respectively. The $\mathrm{K}_{\mathrm{a}}$ of SM/POPC, SM/POPS, and SM/POPE in 70:30 mol\% were 0.18 $\pm 0.09,0.33 \pm 0.3$, and $0.41 \pm 0.31 \mu \mathrm{M}^{-1}$, respectively. The $\mathrm{K}_{\mathrm{a}}$ of $\alpha$-crystallin binding to SM/POPC, SM/POPS, and $\mathrm{SM} / \mathrm{POPE}$ membranes in 50:50 mol\% were $0.26 \pm 0.05,0.79 \pm 0.33$, and $1.45 \pm 0.61 \mu \mathrm{M}^{-1}$, respectively. Statistically significant differences were seen with $\mathrm{p} \leq 0.05$ when the $\mathrm{K}_{\mathrm{a}}$ values of $\alpha$-crystallin binding on two-component mixtures of PL membranes in 70:30 mol\% were compared among each other. Similarly, when the $\mathrm{K}_{\mathrm{a}}$ values of $\alpha$-crystallin binding on two-component mixtures of PL membranes in 50:50 mol\% were compared among each other, statistically significant differences were seen with $\mathrm{p} \leq 0.05$. The error bars in the value of $\mathrm{K}_{\mathrm{a}}$ were calculated from the $95 \%$ confidence interval (profile likelihood) from the one-site ligand binding model. To the best of our knowledge, our attempt is the first to calculate the $\mathrm{K}_{\mathrm{a}}$ of $\alpha$-crystallin binding to two-component mixtures of PL membranes. Interestingly, the $\mathrm{K}_{\mathrm{a}}$ of $\alpha$-crystallin to two-component mixtures of PL membranes (both 70:30 mol\% and 50:50 mol\%) followed the trends: $\mathrm{K}_{\mathrm{a}}(\mathrm{SM} / \mathrm{POPE})>\mathrm{K}_{\mathrm{a}}(\mathrm{SM} / \mathrm{POPS})>\mathrm{K}_{\mathrm{a}}(\mathrm{SM} / \mathrm{POPC})$.

The observed values of $K_{a}$ are peculiar in the sense that POPE, which inhibits the binding most in the form of an individual membrane, mixed with SM gives the highest $\mathrm{K}_{\mathrm{a}}$, and the POPC, which inhibits the binding least in the form of an individual membrane, mixed with SM gives the lowest $\mathrm{K}_{\mathrm{a}}$. It can be the result of headgroup size and charge, $\mathrm{H}-$ bonding between headgroups, and lipid curvature. A combination of all these factors can likely co-occur. As the POPE headgroup is the smallest (Hauser et al., 1981), the headgroup of POPE molecules in the SM/POPE bilayer would 
This is an author-produced, peer-reviewed version of this article. The final, definitive version of this document can be found online at Experimental Eye Research, published by Elsevier. Copyright restrictions may apply. The content of this document may vary from the final published version. https://doi.org/ 10.1016/j.exer.2020.108337

lessen steric clashes between headgroups. Also, the POPE has negative curvature (Hamai et al., 2006), which might increase the spacing between headgroups and better expose SM/POPE bilayer's hydrophobic fatty acid core. These are the likely factors that the SM/POPE membrane has the highest $K_{a}$ for the binding of $\alpha$-crystallin. In SM/POPC membrane, the SM headgroup has H-bond donor and acceptor sites (Saito et al., 2018), and the POPC headgroup has an H-bond acceptor site only (Mainali et al., 2020b; Nylund et al., 2006; Saito et al., 2018). Since the SM and POPC molecule's headgroups are comparable in size (Saito et al., 2018), we speculate that H-bonding between donor of SM and an acceptor of POPC headgroups is more favorable. It may be the likely reason that the hydrophobic core of the $\mathrm{SM} / \mathrm{POPC}$ is more hidden, with the smallest $\mathrm{K}_{\mathrm{a}}$ for the binding of $\alpha$-crystallin. As the size of the POPS headgroup is smaller than the SM headgroup (Jurkiewicz et al., 2012), the POPS headgroup would also lessen the steric clashes between headgroups in SM/POPS membrane. However, the POPS headgroup has a negative charge, which would minimize the hydrophobic interaction between the membrane's hydrophobic fatty acid core and the $\alpha$-crystallin, as stated in (Boyle and Takemoto, 1996; Cenedella and Fleschner, 1992). These are the likely reasons that SM/POPS membrane has higher $\mathrm{K}_{\mathrm{a}}$ than SM/POPC membrane but lower $\mathrm{K}_{\mathrm{a}}$ than SM/POPE membrane.

Each two-component mixture of PL membrane in 50:50 mol\% has a higher value of $\mathrm{K}_{\mathrm{a}}$ than the same two-component mixture of PL membrane in 70:30 mol\% (Fig. 6B and 6D). For SM/POPE membrane, when mol\% of POPE molecules increase, the steric clashes between headgroups decrease more. Also, the increase in the mol\% of POPE increases the spacing between the headgroups, as the POPE has negative curvature. Such effects likely expose the hydrophobic fatty acid core of the SM/POPE membrane more. These are the likely factors that SM/POPE membrane in 50:50 mol\% has higher $\mathrm{K}_{\mathrm{a}}$ for the binding of $\alpha$-crystallin than SM/POPE at 70:30 mol\%. When mol\% of POPC increases in $\mathrm{SM} / \mathrm{POPC}$ bilayer, the chance of forming H-bonds between headgroups in SM/POPC bilayer likely decreases as the number of $\mathrm{H}$-bond donor sites decreases and acceptor sites remains the same in the bilayer due to the presence of the H-bond acceptor site only in the POPC headgroup. It may be the possible reason that SM/POPC membrane in 50:50 $\mathrm{mol} \%$ has higher Ka than at 70:30 mol\%. Since the size of the POPS headgroup is smaller than the SM headgroup, the increase in the mol\% of POPS decreases the steric clashes between headgroups in the SM/POPS membrane. Also, the negative charge in the headgroup of POPS causes repulsion between neighboring POPS molecules. However, the negative charge in the headgroup of POPS molecules minimizes the hydrophobic interaction between the hydrophobic fatty acid core of the membrane and $\alpha$-crystallin. Therefore, the $\mathrm{K}_{\mathrm{a}}$ of SM/POPS membrane in 50:50 mol\% increases compared to $70: 30 \mathrm{~mol} \%$ but remains smaller than for SM/POPE in 50:50 mol\% but larger than for SM/POPC in $50: 50 \mathrm{~mol} \%$.

\subsection{Physical Properties of Two-Component Mixtures of PL Membranes After Binding with $\alpha$-Crystallin}

The physical properties (mobility parameter and maximum splitting) of two-component PL membranes after binding with $\alpha$-crystallin were calculated by using the method explained in section 2.6. Fig. 7A and 7C show the mobility parameter plotted as a function of $\alpha$-crystallin concentration for two-component mixtures of PL membranes in 70:30 mol\% and 50:50 mol\%, respectively. For both $70: 30 \mathrm{~mol} \%$ and 50:50 mol\% samples without $\alpha$-crystallin $(0 \mu \mathrm{M} \alpha$ crystallin), the mobility parameter followed the trends: SM/POPC $>$ SM/POPS $>$ SM/POPE. With an increase in the $\alpha$-crystallin concentration, all the two-component mixtures of PL membranes showed a decrease in the mobility parameter (Fig. 7A and 7C). These results indicate that all the two-component mixtures of PL membranes were immobilized near the headgroup regions when more and more $\alpha$-crystallin bound to the membranes.

Our results suggest that how sharply the mobility parameter decreases depends on the strength of $\alpha$-crystallin binding with the membrane. For example, for both the $70: 30 \mathrm{~mol} \%$ and $50: 50 \mathrm{~mol} \%$ samples, the mobility parameter decreases sharply for SM/POPE membrane and slowly for SM/POPC membrane because the $\mathrm{K}_{\mathrm{a}}$ of $\alpha$-crystallin binding to $\mathrm{SM} / \mathrm{POPE}$ is the largest and to SM/POPC is the least. The data for individual PL membranes further support this claim, i.e., the mobility parameter decreases sharply for POPC and SM membranes compared to the POPS membrane because the $K_{a}$ of $\alpha$-crystallin binding to POPC and SM membranes are larger than the $K_{a}$ of $\alpha$-crystallin binding to POPS membrane (Fig. 3). Additionally, our results suggest that the total decrease of the mobility parameter depends on the maximum percentage of the membrane surface occupied by the $\alpha$-crystallin. For example, for the $70: 30 \mathrm{~mol} \%$ sample, the mobility parameter's overall change is largest for SM/POPE membrane and smallest for SM/POPC membrane because the maximum percentage of membrane surface occupied by $\alpha$-crystallin is largest for SM/POPE membrane and smallest for SM/POPC membrane (Fig. 6A). The observations for individual PL membranes further support this claim, e.g.; the mobility parameter's overall decrease is largest for SM membranes because the percentage of membrane surface occupied by $\alpha$-crystallin on SM membranes is the largest (i.e., $~ 14 \%$ ). 
This is an author-produced, peer-reviewed version of this article. The final, definitive version of this document can be found online at Experimental Eye Research, published by Elsevier. Copyright restrictions may apply. The content of this document may vary from the final published version. https://doi.org/ 10.1016/j.exer.2020.108337

Fig. 7B and 7D show the maximum splitting versus $\alpha$-crystallin concentration curves for two-component mixtures of PL membranes in 70:30 mol\% and 50:50 mol\%, respectively. For both mol\% samples without $\alpha$-crystallin $(0 \mu \mathrm{M} \alpha$ crystallin), the maximum splitting followed the trends: SM/POPE $>$ SM/POPS $>$ SM/POPC. The trends of $\mathrm{K}_{\mathrm{a}}$ for twocomponent mixtures of PL membranes is the same as the trends of the maximum splitting. It may suggest that a more ordered membrane may have the highest $\mathrm{K}_{\mathrm{a}}$ for the binding with $\alpha$-crystallin. Since the trends of maximum splitting and $\mathrm{K}_{\mathrm{a}}$ for individual PL membranes are not the same, we do not know for certain if the higher membrane order gives the higher $\mathrm{K}_{\mathrm{a}}$ for the binding with $\alpha$-crystallin. The maximum splitting increased with an increase in $\alpha$-crystallin concentration for SM/POPE in 70:30 mol\% membrane only. It implies that the membrane (SM/POPE in 70:30 mol\%) became more ordered when more and more $\alpha$-crystallin binds to it. Surprisingly, maximum splitting remained the same for all other two-component mixtures of PL membranes with an increase in $\alpha$-crystallin concentration. Overall, these results show that PLs composition plays a significant role in modulating the membrane's physical properties.

\section{Conclusions}

In conclusion, we reported measurements of percentage of membrane surface occupied by $\alpha$-crystallin and the binding affinity ( $\mathrm{K}_{\mathrm{a}}$ ) of $\alpha$-crystallin to individual PL membranes (i.e., POPE*, POPS, SM, and POPC) as well as to twocomponent mixtures of PL membranes (i.e., SM/POPE, SM/POPS, and SM/POPC in 70:30 and 50:50 mol\%). Except for the POPE* membrane, for which there was no binding of $\alpha$-crystallin, the binding of $\alpha$-crystallin to all other membranes was saturable. The $\mathrm{K}_{\mathrm{a}}$ of $\alpha$-crystallin to individual PL membranes followed the trends: $\mathrm{K}_{\mathrm{a}}(\mathrm{POPC})>$ $\mathrm{K}_{\mathrm{a}}(\mathrm{SM})>\mathrm{K}_{\mathrm{a}}(\mathrm{POPS})>\mathrm{K}_{\mathrm{a}}\left(\mathrm{POPE}^{*}\right)$, indicating POPE* inhibits binding the most whereas POPC inhibits binding the least. Also, the $\mathrm{K}_{\mathrm{a}}$ of $\alpha$-crystallin binding to two-component mixtures of PL membranes followed the trends: $\mathrm{K}_{\mathrm{a}}(\mathrm{SM} / \mathrm{POPE})>\mathrm{K}_{\mathrm{a}}(\mathrm{SM} / \mathrm{POPS})>\mathrm{K}_{\mathrm{a}}(\mathrm{SM} / \mathrm{POPC})$, indicating SM/POPC inhibits binding the most whereas SM/POPE inhibits binding the least. We also reported the physical properties (mobility parameter and the maximum splitting) of the membranes upon binding with $\alpha$-crystallin. The mobility parameter of the membranes decreased when more and more $\alpha$-crystallin was bound to the membranes. It represents that the membrane's headgroup regions become more immobilized when more and more $\alpha$-crystallin binds to them. Surprisingly, an increase in the maximum splitting of only the SM and SM/POPE (70:30 mol\%) membranes was observed, with an increase in $\alpha$-crystallin concentration. It represents that the headgroup regions of only these membranes become more ordered when more and more $\alpha$-crystallin binds to them. Our results show that PL composition plays a significant role in modulating the membrane's physical properties. Our observations suggested that the headgroup's size and charge, hydrogen bonding between headgroups, and lipid curvature modulate the hydrophobic interaction between the hydrophobic fatty acid core of the membranes and $\alpha$-crystallin. These findings contribute to a better understanding of the molecular mechanisms involved in the $\alpha$ crystallin binding to PLs of the eye lens membranes.

Our study clearly shows that the EPR spin-labeling method can be used to probe the molecular interactions between $\alpha$-crystallin and eye lens PL membranes. However, it does not replicate the in-vivo condition of the eye lens membrane and $\alpha$-crystallin. Eye lens membranes compose mixtures of PLs, intrinsic proteins, and high cholesterol levels (Bassnett et al., 2011; Borchman et al., 1989; Cooper, 2000). Also, $\alpha$-crystallin is modified due to post-translational modifications (PTMs) such as deamidation, truncation, oxidation, and phosphorylation (Lampi et al., 1998; Shih et al., 1998). Due to modifications, $\alpha$-crystallin may denature and bind deep into the membranes (Cobb and Petrash, 2002a; Tang et al., 1999). Therefore, a study involving modified $\alpha$-crystallin binding to lens membranes would be more relevant to understand the in-vivo binding of $\alpha$-crystallin to the lens membranes. Even though $\alpha$-crystallin binding with the individual and two-component PL membranes in our case does not replicate the in-vivo conditions of $\alpha$-crystallin and membranes, it clearly shows that unmodified $\alpha$-crystallin binds differently with different individual and two-component PL membranes. Most importantly, our results help to extrapolate that the changes in PL composition with age (Borchman, 2020; Borchman and Yappert, 2010; Huang et al., 2005; Mainali et al., 2017; Paterson et al., 1997; Truscott, 2000; Yappert et al., 2003), among species (Borchman, 2020; Borchman et al., 2017; Deeley et al., 2008; Stimmelmayr and Borchman, 2018), and with locations in the lens (Borchman et al., 2004, 1989; Deeley et al., 2008; Mainali et al., 2017; Raguz et al., 2009; Yappert et al., 2003) are the leading cause of $\alpha$-crystallin binding to lens membranes, resulting in lens opacity and cataract formation. Additionally, it is not surprising that the binding affinities $\left(\mathrm{K}_{\mathrm{a}}\right)$ and the percentages of membrane surface occupied estimated in this study are slightly different from those in the literature (Mulders et al., 1985), where lens plasma membranes were used.

\section{Author Declaration}

The authors report no conflicts of interest. 
This is an author-produced, peer-reviewed version of this article. The final, definitive version of this document can be found online at Experimental Eye Research, published by Elsevier. Copyright restrictions may apply. The content of this document may vary from the final published version. https://doi.org/ 10.1016/j.exer.2020.108337

\section{Acknowledgements}

Research reported in this publication was supported by the National Institutes of Health (USA) under Grant R01 EY030067.

\section{References}

Bassnett, S., Costello, M.J., 2017. The cause and consequence of fiber cell compaction in the vertebrate lens. Exp. Eye Res. 156, 50-57. https://doi.org/10.1016/j.exer.2016.03.009

Bassnett, S., Shi, Y., Vrensen, G.F.J.M., 2011. Biological glass: structural determinants of eye lens transparency. Philos. Trans. R. Soc. B Biol. Sci. 366, 1250-1264. https://doi.org/10.1098/rstb.2010.0302

Borchman, D., 2020. Lipid Conformational Order and the Etiology of Cataract and Dry Eye. J. Lipid Res. https://doi.org/10.1194/jlr.tr120000874

Borchman, D., Byrdwell, W.C., Yappert, M.C., 1994. Regional and age-dependent differences in the phospholipid composition of human lens membranes. Invest. Ophthalmol. Vis. Sci. 35, 3938-3942.

Borchman, D., Delamere, N.A., McCauley, L.A., Paterson, C.A., 1989. Studies on the distribution of cholesterol, phospholipid, and protein in the human and bovine lens. Lens Eye Toxic. Res. 6, 703-724.

Borchman, D., Stimmelmayr, R., George, J.C., 2017. Whales, lifespan, phospholipids, and cataracts. J. Lipid Res. 58, 2289-2298. https://doi.org/10.1194/jlr.M079368

Borchman, D., Tang, D., 1996. Binding capacity of alpha-crystallin to bovine lens lipids. Exp. Eye Res. 63, 407410. https://doi.org/10.1006/exer.1996.0130

Borchman, D., Tang, D., Yappert, M.C., 1999. Lipid composition, membrane structure relationships in lens and muscle sarcoplasmic reticulum membranes. Biospectroscopy 5, 151-167. https://doi.org/10.1002/(SICI)1520-6343(1999)5:3<151::AID-BSPY5>3.0.CO;2-D

Borchman, D., Yappert, M.C., 2010. Lipids and the ocular lens. J. Lipid Res. 51, 2473-2488. https://doi.org/10.1194/jlr.R004119

Borchman, D., Yappert, M.C., Afzal, M., 2004. Lens lipids and maximum lifespan. Exp. Eye Res., Dr Abraham Spector International Symposium 79, 761-768. https://doi.org/10.1016/j.exer.2004.04.004

Bova, M.P., Ding, L.-L., Horwitz, J., Fung, B.K.-K., 1997. Subunit Exchange of aA-Crystallin. J. Biol. Chem. 272, 29511-29517. https://doi.org/10.1074/jbc.272.47.29511

Bova, M.P., McHaourab, H.S., Han, Y., Fung, B.K., 2000. Subunit exchange of small heat shock proteins. Analysis of oligomer formation of alphaA-crystallin and Hsp27 by fluorescence resonance energy transfer and sitedirected truncations. J. Biol. Chem. 275, 1035-1042. https://doi.org/10.1074/jbc.275.2.1035

Boyle, D.L., Takemoto, L., 1996. EM immunolocalization of $\alpha$-crystallins: Association with the plasma membrane from normal and cataractous human lenses. Curr. Eye Res. 15, 577-582. https://doi.org/10.3109/02713689609000769

Bron, A.J., Vrensen, G.F., Koretz, J., Maraini, G., Harding, J.J., 2000. The ageing lens. Ophthalmol. J. Int. Ophtalmol. Int. J. Ophthalmol. Z. Augenheilkd. 214, 86-104. https://doi.org/10.1159/000027475

Buboltz, J.T., 2009. A more efficient device for preparing model-membrane liposomes by the rapid solvent exchange method. Rev. Sci. Instrum. 80, 124301. https://doi.org/10.1063/1.3264073

Buboltz, J.T., Feigenson, G.W., 1999. A novel strategy for the preparation of liposomes: rapid solvent exchange. Biochim. Biophys. Acta 1417, 232-245. https://doi.org/10.1016/s0005-2736(99)00006-1

Burgess, S., 1998. Liposome Preparation - Avanti ${ }^{\circledR}$ Polar Lipids. Sigma-Aldrich. URL https://www.sigmaaldrich.com/technical-documents/articles/biology/liposome-preparation.html

Casal, H.L., Mantsch, H.H., 1984. Polymorphic phase behaviour of phospholipid membranes studied by infrared spectroscopy. Biochim. Biophys. Acta BBA - Rev. Biomembr. 779, 381-401. https://doi.org/10.1016/03044157(84)90017-0

Cenedella, R.J., Chandrasekher, G., 1993. High capacity binding of alpha crystallins to various bovine lens membrane preparations. Curr. Eye Res. 12, 1025-1038. https://doi.org/10.3109/02713689309029230

Cenedella, R.J., Fleschner, C.R., 1992. Selective association of crystallins with lens "native" membrane during dynamic cataractogenesis. Curr. Eye Res. 11, 801-815. https://doi.org/10.3109/02713689209000753

Chandrasekher, G., Cenedella, R.J., 1997. Properties of $\alpha$-crystallin Bound to Lens Membrane: Probing Organization at the Membrane Surface. Exp. Eye Res. 64, 423-430. https://doi.org/10.1006/exer.1996.0228

Chandrasekher, G., Cenedella, R.J., 1995. Protein associated with human lens "native" membrane during aging and cataract formation. Exp. Eye Res. 60, 707-717. https://doi.org/10.1016/s0014-4835(05)80012-0 
This is an author-produced, peer-reviewed version of this article. The final, definitive version of this document can be found online at Experimental Eye Research, published by Elsevier. Copyright restrictions may apply. The content of this document may vary from the final published version. https://doi.org/ 10.1016/j.exer.2020.108337

Cobb, B.A., Petrash, J.M., 2002a. alpha-Crystallin chaperone-like activity and membrane binding in age-related cataracts. Biochemistry 41, 483-490. https://doi.org/10.1021/bi0112457

Cobb, B.A., Petrash, J.M., 2002b. Factors influencing $\alpha$-crystallin association with phospholipid vesicles. Mol. Vis. 8, 85-93.

Cobb, B.A., Petrash, J.M., 2000. Characterization of alpha-crystallin-plasma membrane binding. J. Biol. Chem. 275, 6664-6672. https://doi.org/10.1074/jbc.275.9.6664

Cooper, G.M., 2000. Structure of the Plasma Membrane. Cell Mol. Approach 2nd Ed. https://www.ncbi.nlm.nih.gov/books/NBK9898/

Datiles, M.B., Ansari, R.R., Yoshida, J., Brown, H., Zambrano, A.I., Tian, J., Vitale, S., Zigler, J.S., Ferris, F.L., West, S.K., Stark, W.J., 2016. Longitudinal Study of Age Related Cataract Using Dynamic Light Scattering: Loss of $\alpha$-crystallin Leads to Nuclear Cataract Development. Ophthalmology 123, 248-254. https://doi.org/10.1016/j.ophtha.2015.10.007

Deeley, J.M., Mitchell, T.W., Wei, X., Korth, J., Nealon, J.R., Blanksby, S.J., Truscott, R.J.W., 2008. Human lens lipids differ markedly from those of commonly used experimental animals. Biochim. Biophys. Acta BBA Mol. Cell Biol. Lipids 1781, 288-298. https://doi.org/10.1016/j.bbalip.2008.04.002

Erie, J.C., Pueringer, M.R., Brue, S.M., Chamberlain, A., Hodge, D.O., 2016. Statin Use and Incident Cataract Surgery: A Case-Control Study. Ophthalmic Epidemiol. 23, 40-45. https://doi.org/10.3109/09286586.2015.1077258

Friedrich, M.G., Truscott, R.J.W., 2010. Large-scale binding of $\alpha$-crystallin to cell membranes of aged normal human lenses: a phenomenon that can be induced by mild thermal stress. Invest. Ophthalmol. Vis. Sci. 51, 5145-5152. https://doi.org/10.1167/iovs.10-5261

Friedrich, M.G., Truscott, R.J.W., 2009. Membrane Association of Proteins in the Aging Human Lens: Profound Changes Take Place in the Fifth Decade of Life. Invest. Ophthalmol. Vis. Sci. 50, 4786-4793. https://doi.org/10.1167/iovs.09-3588

Gong, Y., Feng, K., Yan, N., Xu, Y., Pan, C.-W., 2015. Different amounts of alcohol consumption and cataract: a meta-analysis. Optom. Vis. Sci. Off. Publ. Am. Acad. Optom. 92, 471-479. https://doi.org/10.1097/OPX.0000000000000558

Grami, V., Marrero, Y., Huang, L., Tang, D., Yappert, M.C., Borchman, D., 2005. alpha-Crystallin binding in vitro to lipids from clear human lenses. Exp. Eye Res. 81, 138-146. https://doi.org/10.1016/j.exer.2004.12.014

Hamai, C., Yang, T., Kataoka, S., Cremer, P.S., Musser, S.M., 2006. Effect of Average Phospholipid Curvature on Supported Bilayer Formation on Glass by Vesicle Fusion. Biophys. J. 90, 1241-1248. https://doi.org/10.1529/biophysj.105.069435

Hauser, H., Pascher, I., Pearson, R.H., Sundell, S., 1981. Preferred conformation and molecular packing of phosphatidylethanolamine and phosphatidylcholine. Biochim. Biophys. Acta BBA - Rev. Biomembr. 650, 21-51. https://doi.org/10.1016/0304-4157(81)90007-1

Hejtmancik, J.F., Kantorow, M., 2004. Molecular genetics of age-related cataract. Exp. Eye Res. 79, 3-9. https://doi.org/10.1016/j.exer.2004.03.014

Hiratsuka, Y., Li, G., 2001. Alcohol and eye diseases: a review of epidemiologic studies. J. Stud. Alcohol 62, $397-$ 402. https://doi.org/10.15288/jsa.2001.62.397

Hoffer, K.J., 1993. Axial Dimension of the Human Cataractous Lens. Arch. Ophthalmol. 111, 914-918. https://doi.org/10.1001/archopht.1993.01090070032014

Horwitz, J., 2003. Alpha-crystallin. Exp. Eye Res. 76, 145-153. https://doi.org/10.1016/s0014-4835(02)00278-6

Horwitz, J., Bova, M.P., Ding, L.L., Haley, D.A., Stewart, P.L., 1999. Lens alpha-crystallin: function and structure. Eye Lond. Engl. 13 ( Pt 3b), 403-408. https://doi.org/10.1038/eye.1999.114

Horwitz, J., Huang, Q.L., Ding, L., Bova, M.P., 1998. Lens alpha-crystallin: chaperone-like properties. Methods Enzymol. 290, 365-383. https://doi.org/10.1016/s0076-6879(98)90032-5

Huang, J., Buboltz, J.T., Feigenson, G.W., 1999. Maximum solubility of cholesterol in phosphatidylcholine and phosphatidylethanolamine bilayers. Biochim. Biophys. Acta 1417, 89-100. https://doi.org/10.1016/s00052736(98)00260-0

Huang, L., Grami, V., Marrero, Y., Tang, D., Yappert, M.C., Rasi, V., Borchman, D., 2005. Human Lens Phospholipid Changes with Age and Cataract. Invest. Ophthalmol. Vis. Sci. 46, 1682-1689. https://doi.org/10.1167/iovs.04-1155

Ifeanyi, F., Takemoto, L., 1991. Interaction of lens crystallins with lipid vesicles. Exp. Eye Res. 52, 535-538. https://doi.org/10.1016/0014-4835(91)90054-i

Ifeanyi, F., Takemoto, L., 1990a. Alpha crystallin from human cataractous vs. normal lenses: change in binding to lens membrane. Exp. Eye Res. 50, 113-116. https://doi.org/10.1016/0014-4835(90)90017-o 
This is an author-produced, peer-reviewed version of this article. The final, definitive version of this document can be found online at Experimental Eye Research, published by Elsevier. Copyright restrictions may apply. The content of this document may vary from the final published version. https://doi.org/ 10.1016/j.exer.2020.108337

Ifeanyi, F., Takemoto, L., 1990b. Specificity of alpha crystallin binding to the lens membrane. Curr. Eye Res. 9, 259-265. https://doi.org/10.3109/02713689009044521

Ifeanyi, F., Takemoto, L., 1989. Differential binding of alpha-crystallins to bovine lens membrane. Exp. Eye Res. 49, 143-147. https://doi.org/10.1016/0014-4835(89)90082-1

Ignjatović, Z., 1998. [Secondary cataracts in extreme myopia]. Srp. Arh. Celok. Lek. 126, 239-241.

Jacob, S., 2013. Ionizing Radiation as a Risk Factor for Cataract: What about Low-Dose Effects? J. Clin. Exp. Ophthalmol. 04. https://doi.org/10.4172/2155-9570.S1-005

Jurkiewicz, P., Cwiklik, L., Vojtíšková, A., Jungwirth, P., Hof, M., 2012. Structure, dynamics, and hydration of POPC/POPS bilayers suspended in $\mathrm{NaCl}, \mathrm{KCl}$, and $\mathrm{CsCl}$ solutions. Biochim. Biophys. Acta BBA Biomembr. 1818, 609-616. https://doi.org/10.1016/j.bbamem.2011.11.033

Khatry, S.K., Lewis, A.E., Schein, O.D., Thapa, M.D., Pradhan, E.K., Katz, J., 2004. The epidemiology of ocular trauma in rural Nepal. Br. J. Ophthalmol. 88, 456-460. https://doi.org/10.1136/bjo.2003.030700

Klein, R., Klein, B.E., 1997. Diabetic eye disease. The Lancet 350, 197-204. https://doi.org/10.1016/S01406736(97)04195-0

Kuang, T.-M., Tsai, S.-Y., Hsu, W.-M., Cheng, C.-Y., Liu, J.-H., Chou, P., 2005. Body mass index and age-related cataract: the Shihpai Eye Study. Arch. Ophthalmol. Chic. Ill 1960 123, 1109-1114. https://doi.org/10.1001/archopht.123.8.1109

Kusumi, A., Subczynski, W.K., Pasenkiewicz-Gierula, M., Hyde, J.S., Merkle, H., 1986. Spin-label studies on phosphatidylcholine-cholesterol membranes: effects of alkyl chain length and unsaturation in the fluid phase. Biochim. Biophys. Acta 854, 307-317. https://doi.org/10.1016/0005-2736(86)90124-0

Lai, C.-L., Shau, W.-Y., Chang, C.-H., Chen, M.-F., Lai, M.-S., 2013. Statin use and cataract surgery: a nationwide retrospective cohort study in elderly ethnic Chinese patients. Drug Saf. 36, 1017-1024. https://doi.org/10.1007/s40264-013-0076-0

Lampi, K.J., Ma, Z., Hanson, S.R., Azuma, M., Shih, M., Shearer, T.R., Smith, D.L., Smith, J.B., David, L.L., 1998. Age-related changes in human lens crystallins identified by two-dimensional electrophoresis and mass spectrometry. Exp. Eye Res. 67, 31-43. https://doi.org/10.1006/exer.1998.0481

Leske, M.C., Wu, S.Y., Hennis, A., Connell, A.M., Hyman, L., Schachat, A., 1999. Diabetes, hypertension, and central obesity as cataract risk factors in a black population. The Barbados Eye Study. Ophthalmology 106, 35-41. https://doi.org/10.1016/s0161-6420(99)90003-9

Liang, J.J., Li, X.Y., 1992. Spectroscopic studies on the interaction of calf lens membranes with crystallins. Exp. Eye Res. 54, 719-724. https://doi.org/10.1016/0014-4835(92)90026-o

Lipman, R.M., Tripathi, B.J., Tripathi, R.C., 1988. Cataracts induced by microwave and ionizing radiation. Surv. Ophthalmol. 33, 200-210. https://doi.org/10.1016/0039-6257(88)90088-4

Mainali, L., O’Brien, W.J., Timsina, R., 2020a. Interaction of Alpha-Crystallin with Phospholipid Membranes. Curr. Eye Res. https://doi.org/10.1080/02713683.2020.1786131

Mainali, L., Pasenkiewicz-Gierula, M., Subczynski, W.K., 2020b. Formation of cholesterol Bilayer Domains Precedes Formation of Cholesterol Crystals in Membranes Made of the Major Phospholipids of Human Eye Lens Fiber Cell Plasma Membranes. Curr. Eye Res. 45, 162-172. https://doi.org/10.1080/02713683.2019.1662058

Mainali, L., Raguz, M., O’Brien, W.J., Subczynski, W.K., 2017. Changes in the Properties and Organization of Human Lens Lipid Membranes Occurring with Age. Curr. Eye Res. 42, 721-731. https://doi.org/10.1080/02713683.2016.1231325

Mainali, L., Raguz, M., Subczynski, W.K., 2012. Phases and domains in sphingomyelin-cholesterol membranes: structure and properties using EPR spin-labeling methods. Eur. Biophys. J. EBJ 41, 147-159. https://doi.org/10.1007/s00249-011-0766-4

Mainali, L., Vasquez-Vivar, J., Hyde, J.S., Subczynski, W.K., 2015. Spin-labeled small unilamellar vesicles with the T1-sensitive saturation-recovery EPR display as an oxygen sensitive analyte for measurement of cellular respiration. Appl. Magn. Reson. 46, 885-895. https://doi.org/10.1007/s00723-015-0684-1

Metge, P., Donnadieu, M., 1993. [Myopia and cataract]. Rev. Prat. 43, 1784-1786.

Mulders, J.W., Stokkermans, J., Leunissen, J.A., Benedetti, E.L., Bloemendal, H., de Jong, W.W., 1985. Interaction of alpha-crystallin with lens plasma membranes. Affinity for MP26. Eur. J. Biochem. 152, 721-728. https://doi.org/10.1111/j.1432-1033.1985.tb09253.x

Mulders, J.W., Wajcik, E., Bloemendal, H., de Jong, W.W., 1989. Loss of high-affinity membrane binding of bovine nuclear alpha-crystallin. Exp. Eye Res. 49, 149-152. https://doi.org/10.1016/0014-4835(89)90083-3

Négrel, A.-D., Thylefors, B., 1998. The global impact of eye injuries. Ophthalmic Epidemiol. 5, 143-169. https://doi.org/10.1076/opep.5.3.143.8364 
This is an author-produced, peer-reviewed version of this article. The final, definitive version of this document can be found online at Experimental Eye Research, published by Elsevier. Copyright restrictions may apply. The content of this document may vary from the final published version. https://doi.org/ 10.1016/j.exer.2020.108337

Nylund, M., Kjellberg, M.A., Molotkovsky, J.G., Byun, H.-S., Bittman, R., Mattjus, P., 2006. Molecular features of phospholipids that affect glycolipid transfer protein-mediated galactosylceramide transfer between vesicles. Biochim. Biophys. Acta BBA - Biomembr. 1758, 807-812. https://doi.org/10.1016/j.bbamem.2006.04.023

Paterson, C.A., Zeng, J., Husseini, Z., Borchman, D., Delamere, N.A., Garland, D., Jimenez-Asensio, J., 1997. Calcium ATPase activity and membrane structure in clear and cataractous human lenses. Curr. Eye Res. 16, 333-338. https://doi.org/10.1076/ceyr.16.4.333.10689

Pollreisz, A., Schmidt-Erfurth, U., 2010. Diabetic Cataract—Pathogenesis, Epidemiology and Treatment [WWW Document]. J. Ophthalmol. https://doi.org/10.1155/2010/608751

Raguz, M., Mainali, L., Widomska, J., Subczynski, W.K., 2011. Using spin-label electron paramagnetic resonance (EPR) to discriminate and characterize the cholesterol bilayer domain. Chem. Phys. Lipids 164, 819-829. https://doi.org/10.1016/j.chemphyslip.2011.08.001

Raguz, M., Widomska, J., Dillon, J., Gaillard, E.R., Subczynski, W.K., 2009. Physical properties of the lipid bilayer membrane made of cortical and nuclear bovine lens lipids: EPR spin-labeling studies. Biochim. Biophys. Acta 1788, 2380-2388. https://doi.org/10.1016/j.bbamem.2009.09.005

Reddy, G.B., Kumar, P.A., Kumar, M.S., 2006. Chaperone-like activity and hydrophobicity of alpha-crystallin. IUBMB Life 58, 632-641. https://doi.org/10.1080/15216540601010096

Ryazantsev, S.N., Poliansky, N.B., Chebotareva, N.A., Muranov, K.O., 2018. 3D structure of the native $\alpha$-crystallin from bovine eye lens. Int. J. Biol. Macromol. 117, 1289-1298. https://doi.org/10.1016/j.ijbiomac.2018.06.004

Saito, H., Morishita, T., Mizukami, T., Nishiyama, K., Kawaguchi, K., Nagao, H., 2018. Molecular dynamics study of binary POPC bilayers: molecular condensing effects on membrane structure and dynamics. J. Phys. Conf. Ser. 1136, 012022. https://doi.org/10.1088/1742-6596/1136/1/012022

Santhoshkumar, P., Raju, M., Sharma, K.K., 2011. $\alpha$ A-crystallin peptide SDRDKFVIFLDVKHF accumulating in aging lens impairs the function of $\alpha$-crystallin and induces lens protein aggregation. PloS One 6, e19291. https://doi.org/10.1371/journal.pone.0019291

Sato, H., Borchman, D., Ozaki, Y., Lamba, O.P., Byrdwell, W.C., Yappert, M.C., Paterson, C.A., 1996. Lipidprotein interactions in human and bovine lens membranes by Fourier transform Raman and infrared spectroscopies. Exp. Eye Res. 62, 47-53. https://doi.org/10.1006/exer.1996.0006

Schreier, S., Polnaszek, C.F., Smith, I.C., 1978. Spin labels in membranes. Problems in practice. Biochim. Biophys. Acta 515, 395-436. https://doi.org/10.1016/0304-4157(78)90011-4

Schultz, K.M., Feix, J.B., Klug, C.S., 2013. Disruption of LptA oligomerization and affinity of the LptA-LptC interaction. Protein Sci. Publ. Protein Soc. 22, 1639-1645. https://doi.org/10.1002/pro.2369

Schultz, K.M., Lundquist, T.J., Klug, C.S., 2017. Lipopolysaccharide binding to the periplasmic protein LptA. Protein Sci. Publ. Protein Soc. 26, 1517-1523. https://doi.org/10.1002/pro.3177

Sendecki, A.M., Poyton, M.F., Baxter, A.J., Yang, T., Cremer, P.S., 2017. Supported Lipid Bilayers with Phosphatidylethanolamine as the Major Component. Langmuir 33, 13423-13429. https://doi.org/10.1021/acs.langmuir.7b02323

Shiels, A., Hejtmancik, J.F., 2007. Genetic Origins of Cataract. Arch. Ophthalmol. 125, 165-173. https://doi.org/10.1001/archopht.125.2.165

Shih, M., Lampi, K.J., Shearer, T.R., David, L.L., 1998. Cleavage of beta crystallins during maturation of bovine lens. Mol. Vis. 4, 4.

Slater, S.J., Ho, C., Taddeo, F.J., Kelly, M.B., Stubbs, C.D., 1993. Contribution of hydrogen bonding to lipid-lipid interactions in membranes and the role of lipid order: Effects of cholesterol, increased phospholipid unsaturation, and ethanol. Biochemistry 32, 3714-3721. https://doi.org/10.1021/bi00065a025

Slotte, J.P., 2016. The importance of hydrogen bonding in sphingomyelin's membrane interactions with co-lipids. Biochim. Biophys. Acta BBA - Biomembr. 1858, 304-310. https://doi.org/10.1016/j.bbamem.2015.12.008

Solberg, Y., Rosner, M., Belkin, M., 1998. The association between cigarette smoking and ocular diseases. Surv. Ophthalmol. 42, 535-547. https://doi.org/10.1016/s0039-6257(98)00002-2

Srinivas, P., Narahari, A., Petrash, J.M., Swamy, M.J., Reddy, G.B., 2010. Importance of Eye Lens $\alpha$-Crystallin Heteropolymer with 3:1 $\alpha \mathrm{A}$ to $\alpha \mathrm{B}$ Ratio: Stability, Aggregation, and Modifications. IUBMB Life 62, 693702. https://doi.org/10.1002/iub.373

Stimmelmayr, R., Borchman, D., 2018. Lens Lipidomes among phocids and Odobenidae. Aquat. Mamm. 44, 496508. https://doi.org/10.1578/AM.44.5.2018.506

Su, S.-P., McArthur, J.D., Friedrich, M.G., Truscott, R.J.W., Aquilina, J.A., 2011. Understanding the $\alpha$-crystallin cell membrane conjunction. Mol. Vis. 17, 2798-2807. 
This is an author-produced, peer-reviewed version of this article. The final, definitive version of this document can be found online at Experimental Eye Research, published by Elsevier. Copyright restrictions may apply. The content of this document may vary from the final published version. https://doi.org/ 10.1016/j.exer.2020.108337

Subczynski, W.K., Felix, C.C., Klug, C.S., Hyde, J.S., 2005. Concentration by centrifugation for gas exchange EPR oximetry measurements with loop-gap resonators. J. Magn. Reson. San Diego Calif 1997 176, 244-248. https://doi.org/10.1016/j.jmr.2005.06.011

Tang, D., Borchman, D., 1998. Temperature induced structural changes of beta-crystallin and sphingomyelin binding. Exp. Eye Res. 67, 113-118. https://doi.org/10.1006/exer.1998.0497

Tang, D., Borchman, D., Yappert, M.C., 1999. Alpha-crystallin/lens lipid interactions using resonance energy transfer. Ophthalmic Res. 31, 452-462. https://doi.org/10.1159/000055571

Tang, D., Borchman, D., Yappert, M.C., Cenedella, R.J., 1998. Influence of cholesterol on the interaction of alphacrystallin with phospholipids. Exp. Eye Res. 66, 559-567. https://doi.org/10.1006/exer.1997.0467

Tate, M.W., Eikenberry, E.F., Turner, D.C., Shyamsunder, E., Gruner, S.M., 1991. Nonbilayer phases of membrane lipids. Chem. Phys. Lipids 57, 147-164. https://doi.org/10.1016/0009-3084(91)90073-K

Truscott, R.J., 2000. Age-related nuclear cataract: a lens transport problem. Ophthalmic Res. 32, 185-194. https://doi.org/10.1159/000055612

Truscott, R.J.W., 2005. Age-related nuclear cataract-oxidation is the key. Exp. Eye Res. 80, 709-725. https://doi.org/10.1016/j.exer.2004.12.007

Tsvetkova, N.M., Horváth, I., Török, Z., Wolkers, W.F., Balogi, Z., Shigapova, N., Crowe, L.M., Tablin, F., Vierling, E., Crowe, J.H., Vígh, L., 2002. Small heat-shock proteins regulate membrane lipid polymorphism. Proc. Natl. Acad. Sci. 99, 13504-13509. https://doi.org/10.1073/pnas.192468399

Uwineza, A., Kalligeraki, A.A., Hamada, N., Jarrin, M., Quinlan, R.A., 2019. Cataractogenic load - A concept to study the contribution of ionizing radiation to accelerated aging in the eye lens. Mutat. Res. Mutat. Res. 779, 68-81. https://doi.org/10.1016/j.mrrev.2019.02.004

Van den Oetelaar, P.J.M., Van Someren, P.F.H.M., Thomson, J.A., Siezen, R.J., Hoenders, H.J., 1990. A dynamic quaternary structure of bovine .alpha.-crystallin as indicated from intermolecular exchange of subunits. Biochemistry 29, 3488-3493. https://doi.org/10.1021/bi00466a010

Wang, J.J., Rochtchina, E., Tan, A.G., Cumming, R.G., Leeder, S.R., Mitchell, P., 2009. Use of inhaled and oral corticosteroids and the long-term risk of cataract. Ophthalmology 116, 652-657. https://doi.org/10.1016/j.ophtha.2008.12.001

Weintraub, J.M., Willett, W.C., Rosner, B., Colditz, G.A., Seddon, J.M., Hankinson, S.E., 2002. A prospective study of the relationship between body mass index and cataract extraction among US women and men. Int. J. Obes. Relat. Metab. Disord. J. Int. Assoc. Study Obes. 26, 1588-1595. https://doi.org/10.1038/sj.ijo.0802158

Yappert, M.C., Rujoi, M., Borchman, D., Vorobyov, I., Estrada, R., 2003. Glycero- versus sphingo-phospholipids: correlations with human and non-human mammalian lens growth. Exp. Eye Res. 76, 725-734. https://doi.org/10.1016/S0014-4835(03)00051-4

Zhang, W.Z., Augusteyn, R.C., 1994. On the interaction of alpha-crystallin with membranes. Curr. Eye Res. 13, 225-230. https://doi.org/10.3109/02713689408995781

Zhang, Z.Z., Zeng, J.J., Yin, H.H., Tang, D.D., Borchman, D.D., Paterson, C.A.C., 1999. Membrane lipid acrystallin interaction and membrane Ca2+-ATPase activities. Curr. Eye Res. 18, 56-61. https://doi.org/10.1076/ceyr.18.1.56.5387

Zhu, X., Gaus, K., Lu, Y., Magenau, A., Truscott, R.J.W., Mitchell, T.W., 2010. $\alpha$ - and $\beta$-Crystallins Modulate the Head Group Order of Human Lens Membranes during Aging. Invest. Ophthalmol. Vis. Sci. 51, 5162-5167. https://doi.org/10.1167/iovs.09-4947 
Figure Captions

CSL

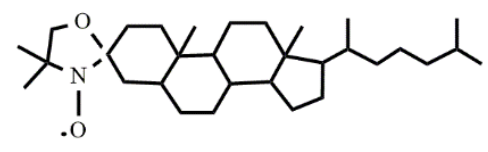

POPC<smiles>CCCCCCCCCCCCCCCCCCCCCCCCC(=O)OCC(COC(=O)OCC[N+](C)(C)C)OC(=O)CCCCCC</smiles>

POPS<smiles>CCCCCCCCCCCCCCCCCCCCCCC(=O)OCC(COP(=O)([O-])OC([NH3+])C(=O)O)OC(=O)CCCCCCC</smiles>

SM<smiles></smiles>

POPE

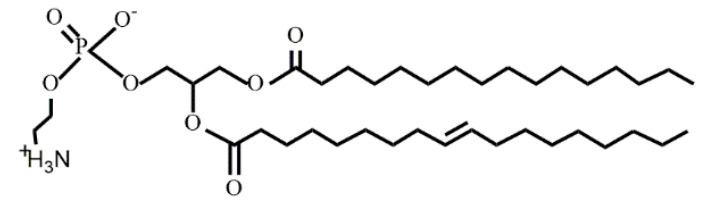

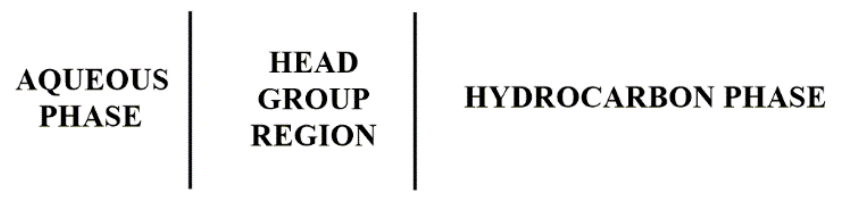

Fig. 1. The chemical structure of cholesterol analog spin-label (CSL), and four major PLs of fiber cell plasma membranes of the eye lens, i.e., POPC, POPS, SM, and POPE. Approximate locations of these molecules across the lipid bilayer membrane are indicated. 

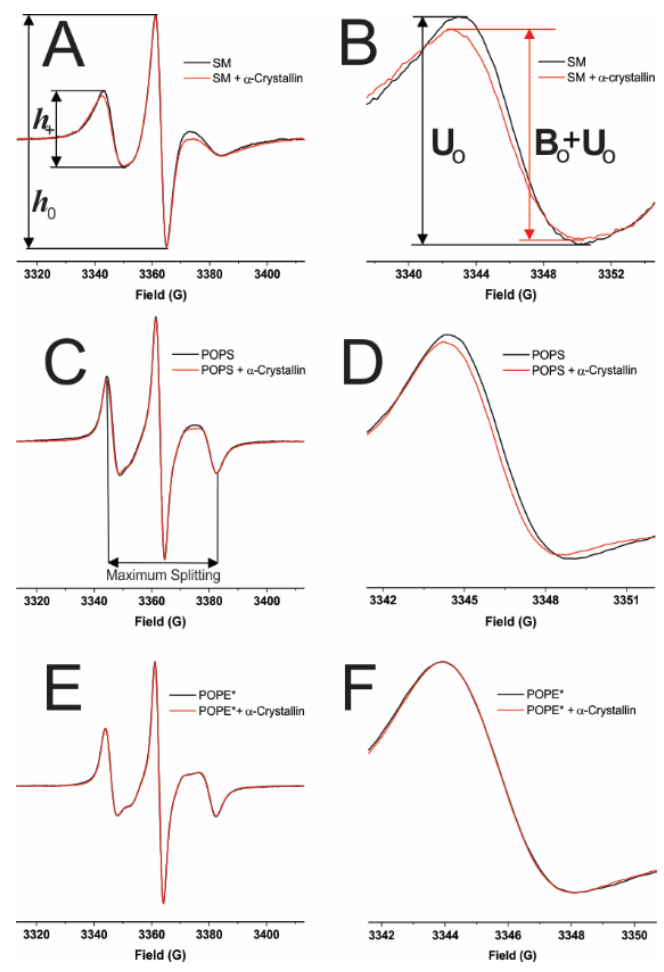

Fig. 2. Representative EPR spectra of CSL in individual PL membranes in the absence of $\alpha$-crystallin (black) and 52.6 $\mu \mathrm{M} \alpha$-crystallin (red). Each spectrum was normalized with respect to peak to peak intensity of the central line. (A), (C), and (E) represent the EPR spectra for SM, POPS, and POPE* (asterisk indicates the presence of $30 \mathrm{~mol} \%$ of POPC) membranes, respectively. (B), (D), and (F) represent the zoomed low field line of the spectra in (A), (C), and (E), respectively. The concentration of PL membranes was fixed at $9.4 \mathrm{mM}$, and the concentration of $\alpha$-crystallin was varied $(0-52.6 \mu \mathrm{M})$. All the samples were incubated at $37^{\circ} \mathrm{C}$ for $16 \mathrm{hr}$, and EPR measurements were taken at $37^{\circ} \mathrm{C}$. The ratio of peak to peak intensity of low field line $\left(\mathrm{h}_{+}\right)$and the central line $\left(\mathrm{h}_{0}\right)$ of EPR spectra was used to calculate the mobility parameter $\left(h_{+} / h_{0}\right)$ of the PL membrane (see Fig. 2A). Peak to peak intensity of low field EPR line of unbound $\left(\mathrm{U}_{0}\right)$ and unbound plus bound $\left(\mathrm{U}_{0}+\mathrm{B}_{0}\right)$ contributions was used to calculate the binding affinity of $\alpha$-crystallin to PL membrane (see Fig. 2B). The horizontal distance between the low field and high field lines in the EPR spectra was used to calculate the maximum splitting (see Fig. 2C) 
This is an author-produced, peer-reviewed version of this article. The final, definitive version of this document can be found online at Experimental Eye Research, published by Elsevier. Copyright restrictions may apply. The content of this document may vary from the final published version. https://doi.org/ 10.1016/j.exer.2020.108337
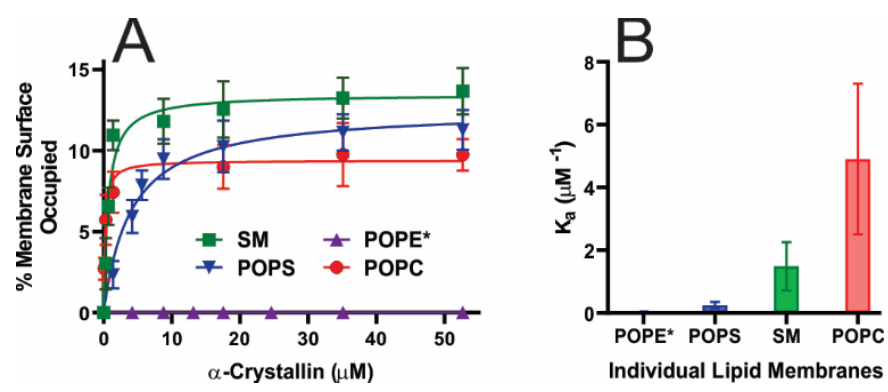

Fig. 3. (A) The percentage of membrane surface occupied plotted as a function of $\alpha$-crystallin concentration for individual PL membranes, i.e., POPE*, POPS, SM, and POPC membranes. The data for the POPC membrane was taken from our recent study (Mainali et al., 2020a). The concentration of $\alpha$-crystallin was varied $(0-52.6 \mu \mathrm{M})$ and PL membranes was fixed at $9.4 \mathrm{mM}$. The mixture of $\alpha$-crystallin and membrane samples were incubated at $37{ }^{\circ} \mathrm{C}$ for $16 \mathrm{hr}$. The percentage of membrane surface occupied by the $\alpha$-crystallin was calculated by using equation (2). The data points were fitted with a one-site ligand binding model in GraphPad Prism (San Diego, CA) to estimate the binding affinity $\left(\mathrm{K}_{\mathrm{a}}\right)$. The error bars were calculated from the average of three independent experiments. (B) Bar plot of $\mathrm{K}_{\mathrm{a}}$ (obtained from (A)) for four major PL membranes. The error bars in (B) were calculated from the $95 \%$ confidence interval (profile likelihood) for the value of $\mathrm{K}_{\mathrm{a}}$.
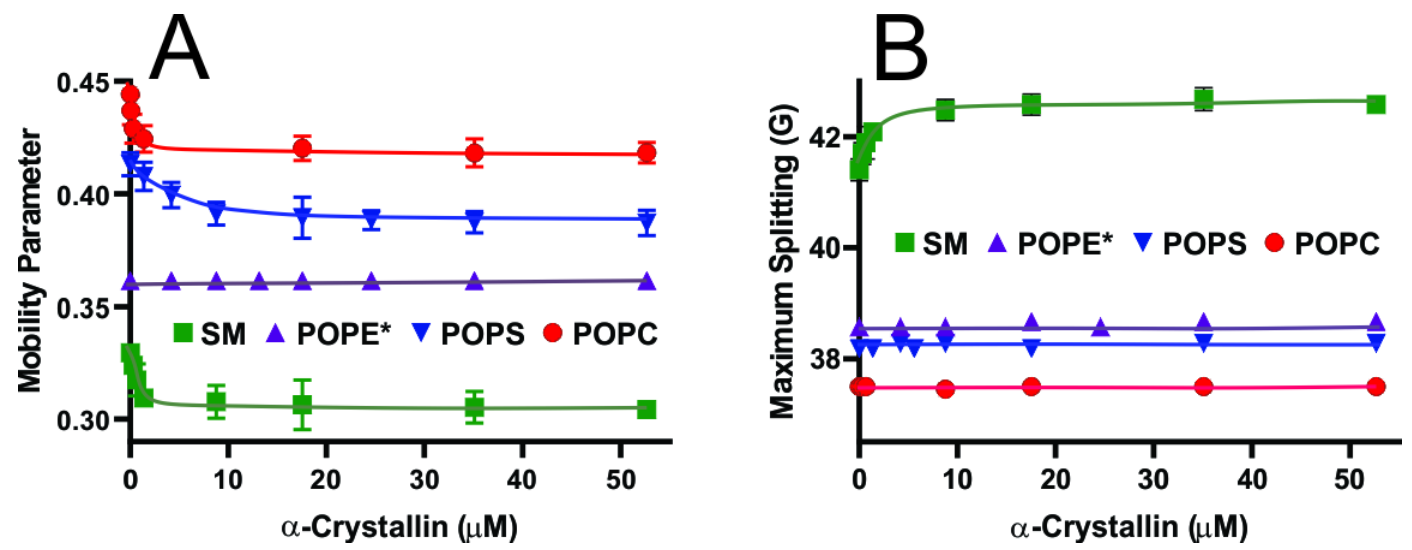

Fig. 4. The physical properties of individual PL membranes plotted as a function of $\alpha$-crystallin concentration. (A) Profiles of the mobility parameter $\left(\mathrm{h}_{+} / \mathrm{h}_{0}\right)$ plotted as a function of $\alpha$-crystallin concentration. (B) Profiles of the maximum splitting plotted as a function of $\alpha$-crystallin concentration. The data (mobility parameter) for the POPC membrane was taken from our previous study (Mainali et al., 2020a). Error bars were estimated from the average of three independent experiments. The concentration of $\alpha$-crystallin was varied $(0-52.6 \mu \mathrm{M})$, and the concentration of PL membranes was fixed at $9.4 \mathrm{mM}$. Each sample was incubated at $37^{\circ} \mathrm{C}$ for $16 \mathrm{hr}$. The mobility parameter and maximum splitting were calculated by using the method explained in section 2.6. 

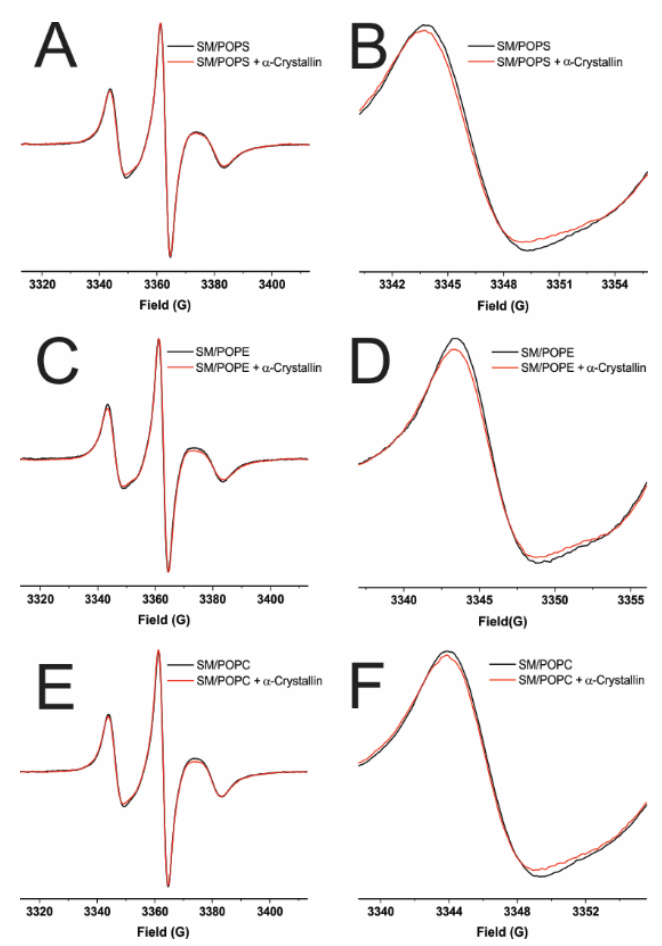

Fig. 5. Representative EPR spectra of CSL in two-component mixtures of PL membranes (70:30 mol\%) in the absence (black) and the presence of $52.6 \mu \mathrm{M} \alpha$-crystallin (red). Each spectrum was normalized with respect to peak to peak intensity of the central EPR line. (A), (C), and (E) represent the EPR spectra for SM/POPS, SM/POPE, and SM/POPS in 70:30 mol\%, respectively. (B), (D), and (F) represent the zoomed low field line of the spectra in (A), (C), and (E), respectively. The concentration of two-component mixtures of PL membranes was fixed at $9.4 \mathrm{mM}$, and the concentration of $\alpha$-crystallin was varied $(0-52.6 \mu \mathrm{M})$. Each sample was incubated at $37^{\circ} \mathrm{C}$ for $16 \mathrm{hr}$, and EPR spectra were recorded at $37^{\circ} \mathrm{C}$. 
This is an author-produced, peer-reviewed version of this article. The final, definitive version of this document can be found online at Experimental Eye Research, published by Elsevier. Copyright restrictions may apply. The content of this document may vary from the final published version. https://doi.org/ 10.1016/j.exer.2020.108337
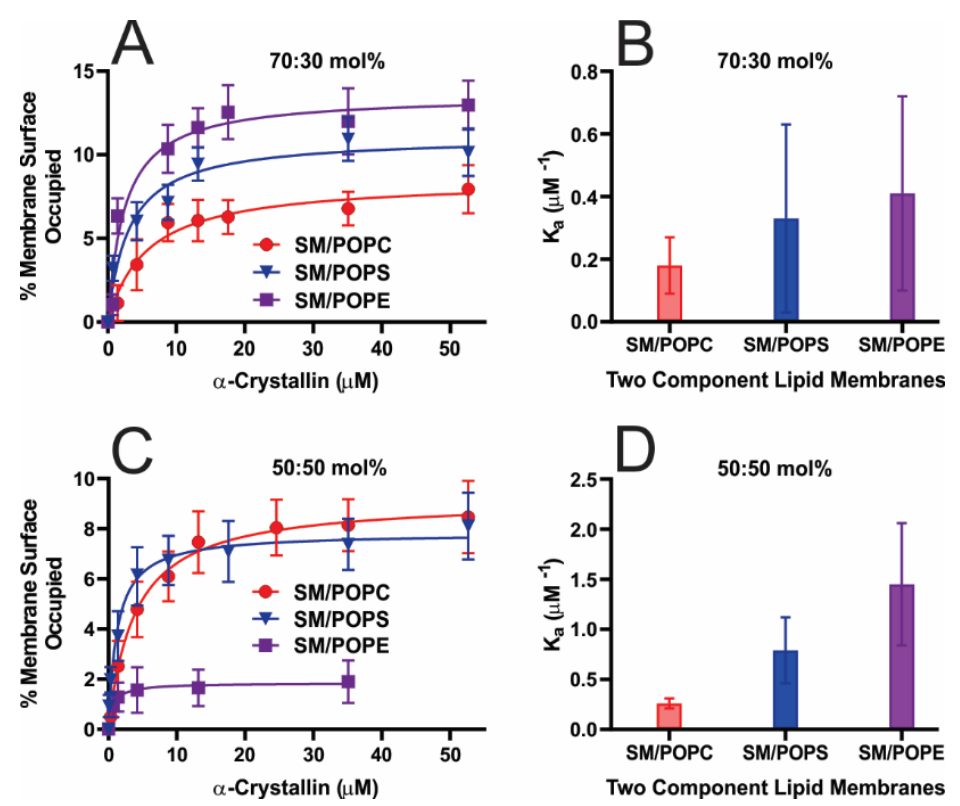

Fig. 6. (A) The percentage of membrane surface occupied plotted as a function of $\alpha$-crystallin concentration for twocomponent mixtures of PL membranes SM/POPC, SM/POPS, and SM/POPE in 70:30 mol\%. (B) Bar plot of $\mathrm{K}_{\mathrm{a}}$ of $\alpha$ crystallin to two-component mixtures of PL membranes in 70:30 mol\% (obtained from (A)). (C) The percentage of membrane surface occupied plotted as a function of $\alpha$-crystallin concentration for two-component mixtures of PL membranes SM/POPC, SM/POPS, and SM/POPE in 50:50 mol\%. (D) Bar plot of $\mathrm{K}_{\mathrm{a}}$ of $\alpha$-crystallin to two-component mixtures of PL membranes in 50:50 mol\% (obtained from (C)). The concentration of $\alpha$-crystallin was varied $(0-52.6$ $\mu \mathrm{M})$, and the concentration of PL membranes was fixed at $9.4 \mathrm{mM}$. The mixture of $\alpha$-crystallin and membrane samples were incubated at $37{ }^{\circ} \mathrm{C}$ for $16 \mathrm{hr}$. The data points in (A) and (C) were fitted with a one-site ligand binding model by using GraphPad Prism (San Diego, CA) to estimate the binding affinity $\mathrm{K}_{\mathrm{a}}$. The error bars in (A) and (C) were estimated from the average of three independent experiments. The error bars in (B) and (D) were calculated from the $95 \%$ confidence interval (profile likelihood) for the respective value of $K_{a}$. 
This is an author-produced, peer-reviewed version of this article. The final, definitive version of this document can be found online at Experimental Eye Research, published by Elsevier. Copyright restrictions may apply. The content of this document may vary from the final published version. https://doi.org/ 10.1016/j.exer.2020.108337
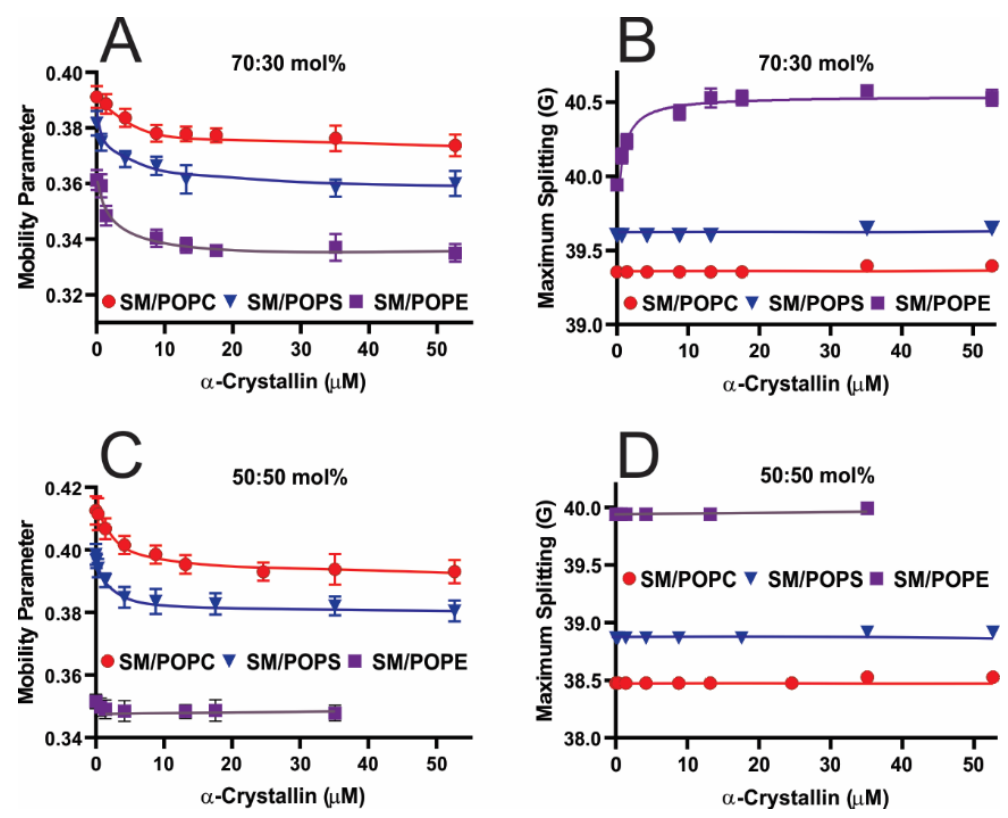

Fig. 7. The physical properties of two-component mixtures of PL membranes plotted as a function of $\alpha$-crystallin concentration. (A) and (B) represent the profiles of mobility parameter $\left(\mathrm{h}_{+} / \mathrm{h}_{0}\right)$ and maximum splitting, respectively, plotted as a function of $\alpha$-crystallin concentration for two-component mixtures of PL membranes in 70:30 mol\%. (C) and (D) represent the profiles of mobility parameter $\left(\mathrm{h}_{+} / \mathrm{h}_{0}\right)$ and maximum splitting, respectively, plotted as a function of $\alpha$-crystallin concentration for two-component mixtures of PL membranes in 50:50 mol\%. The concentration of $\alpha$-crystallin was varied $(0-52.6 \mu \mathrm{M})$, and the concentration of PL membranes was fixed at $9.4 \mathrm{mM}$. Each sample was incubated at $37^{\circ} \mathrm{C}$ for $16 \mathrm{hr}$. The mobility parameter and maximum splitting were calculated by using the method explained in section 2.6. The error bars were estimated from the average of three independent experiments. 